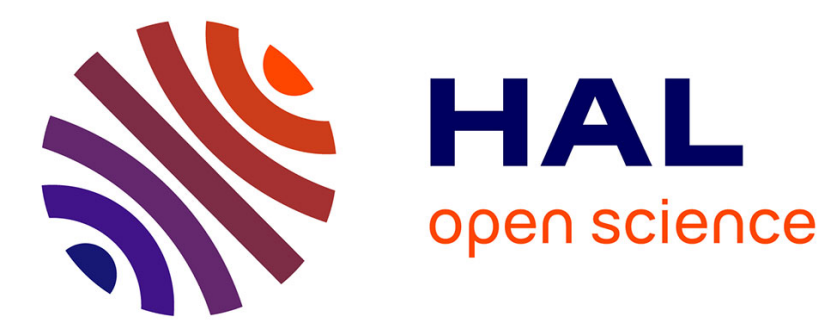

\title{
Comparison study of the gas-phase oxidation of alkylbenzenes and alkylcyclohexanes
}

Olivier Herbinet, Benoit Husson, Hervé Le Gall, Frédérique Battin-Leclerc

\section{To cite this version:}

Olivier Herbinet, Benoit Husson, Hervé Le Gall, Frédérique Battin-Leclerc. Comparison study of the gas-phase oxidation of alkylbenzenes and alkylcyclohexanes. Chemical Engineering Science, 2015, 131, pp.49-62. 10.1016/j.ces.2015.03.026 . hal-01144243

\section{HAL Id: hal-01144243 \\ https://hal.science/hal-01144243}

Submitted on 21 Apr 2015

HAL is a multi-disciplinary open access archive for the deposit and dissemination of scientific research documents, whether they are published or not. The documents may come from teaching and research institutions in France or abroad, or from public or private research centers.
L'archive ouverte pluridisciplinaire HAL, est destinée au dépôt et à la diffusion de documents scientifiques de niveau recherche, publiés ou non, émanant des établissements d'enseignement et de recherche français ou étrangers, des laboratoires publics ou privés. 


\title{
Comparison study of the gas-phase oxidation of alkylbenzenes and alkylcyclohexanes
}

\author{
Olivier Herbinet, Benoit Husson, Hervé Le Gall, Frédérique Battin-Leclerc
}

\author{
Laboratoire Réactions et Génie de Procédés, CNRS, Université de Lorraine, \\ 1 rue Grandville, BP 20451, 54001 NANCY Cedex, France
}

\section{Highlights}

- The gas-phase oxidation of alkylbenzenes and alkylcyclohexanes was studied.

- The alkylbenzene reactivity strongly increases with the size of the alkyl chain.

- The alkylcyclohexane reactivity does not vary with the size of the alkyl chain.

- Alkylcyclohexanes are more reactive than the alkylbenzenes of the same size.

- High fuel/air ratio promotes the formation of heavy oxygenated products.

\begin{abstract}
The goal of this paper is to present new experimental results obtained during the study of the gas phase oxidation of ethyl-benzene, $n$-hexyl-benzene, ethyl-cyclohexane and $n$-butyl-cyclohexane which belongs to two molecule families present in diesel fuels: alkylbenzenes and alkylcyclohexanes. Experiments were carried out in a jet-stirred reactor over the temperature range 550-1100 K. The new results have been compared with existing literature data obtained for alkylbenzenes and alkylcyclohexanes with alkyl chains of different size to highlight the influence of the chain size on the reactivity. The comparison showed that both alkylcyclohexanes exhibit reactivity at both low- and hightemperatures such as cyclohexane and that the reactivity was similar whatever the size of the alkyl chain. For the three compared alkylbenzenes, important differences were observed in the reactivity at low-temperature: ethylbenzene started to react only above $750 \mathrm{~K}$, while other compounds reacted from $550 \mathrm{~K}$. The comparison also showed that alkylbenzenes were less reactive than their alkylcyclohexane homologs and that the production of aromatic compounds known to promote soot formation was also significantly larger for alkylbenzenes. This paper also presents the effect of the equivalence ratio and pressure on the reaction kinetics. In a general manner, a decrease of the fuel/air ratio significantly increased the reactivity and the carbon monoxide selectivity below $800 \mathrm{~K}$, but
\end{abstract}


decreased the selectivity of heavy oxygenated products, the atmospheric degradation of which can be a source of toxic oxygenated products. This decrease had a more limited effect on the reactivity at higher temperatures but disfavored the production of unburned species (oxygenated species like acetaldehyde and unsaturated hydrocarbons which are known to be soot precursors). A pressure increase from 1 to 10 bar enhanced the reactivity of all these hydrocarbons over the full studied temperature range, with a start of the reaction at lower temperatures. A larger production of toxic oxygenated products was observed with increasing pressures, while low pressures promoted the formation of soot precursors. Alkylbenzene results were generally well reproduced by simulations using literature models.

Keywords: Alkylbenzenes; Alkylcyclohexanes; Oxidation; Jet-stirred reactor; Diesel fuel; Fuel/air ratio

\section{Introduction}

As described by Dec (2009), the development of advanced internal combustion engines strategies (e.g. low-temperature combustion (LTC) diesel and homogenous charge compression ( $\mathrm{HCCl}$ ) engines), which are needed to meet future strict emission and fuel consumption regulations, certainly requires a good understanding of the chemistry of fuel ignition and oxidation. As reviewed by Pitz and Mueller (2011), among automotive fuels, diesel fuel is a complex mixture of molecules containing from 10 to 20 carbon atoms. These molecules consist of alkanes (approximately $30 \%$ by mass), alkylcyclohexanes (approximately 24\%), alkyldecalines (approximately 15\%), alkylbenzenes (approximately 10\%) and polycyclic naphthenoaromatic compounds (Guibet, 1999). The ignition and oxidation chemistry of these four last reactant families is still notably less clearly understood than that of alkanes which has been long ago well-mastered (Ranzi et al., 1995, Curran et al., 1998 and Battin-Leclerc et al., 2000) and whose modeling is continuously improving (Sarathy et al., 2011). Because of the increasing use of oil sands and shale, which have higher cycloalkane contents than conventional crude oil sources, the role of cycloalkanes should be more important for transportation fuels in the near future (Xiao et al., 2013). As their influence on engine emissions is important as shown by Dec (2009), the impact on oxidation chemistry of fuel composition, fuel/air ratio and pressure need to be well characterized. Note also that the presence of aromatics and cycloalkanes in fuel is well known for playing a significant role in the formation of soot particulates which have deleterious health effects (Wang, 2011). Table 1 presents the cetane numbers of a few alkylbenzenes and alkylcyclohexanes (Santana et al., 2006) which measure their combustion quality during the compression in a diesel engine (Kamimoto and Kobayashi, 1991). The cetane number of $C_{1}-C_{7}$ alkylbenzenes increases notably when increasing the size of the 
alkyl chain. Those of $\mathrm{C}_{2}-\mathrm{C}_{4}$ alkylcyclohexanes remain similar, but are significantly higher than that of cyclohexane and those of all $\mathrm{C}_{1}-\mathrm{C}_{7}$ alkylbenzenes.

Table 1: Structure and cetane number of several alkylbenzenes and alkylcyclohexanes according to Santana et al. (2006). The names of the fuels investigated in this study are in bold.

\begin{tabular}{|c|c|c|c|}
\hline Name & $\begin{array}{l}\text { Abbreviated name in the } \\
\text { paper }\end{array}$ & Structure & $\begin{array}{l}\text { Cetane } \\
\text { number }\end{array}$ \\
\hline ethylbenzene & $\varphi C_{2} H_{5}$ & & 8 \\
\hline$n$-butylbenzene & $\varphi C_{4} H_{9}$ & & $\begin{array}{c}\text { not } \\
\text { available }\end{array}$ \\
\hline$n$-pentylbenzene & $\varphi C_{5} H_{11}$ & & 13 \\
\hline$n$-hexylbenzene & $\varphi C_{6} H_{13}$ & & 26 \\
\hline$n$-heptylbenzene & $\varphi C_{7} H_{15}$ & & 35 \\
\hline cyclohexane & $\sigma H$ & & 15 \\
\hline ethylcyclohexane & $\sigma C_{2} H_{5}$ & & 45 \\
\hline$n$-butylcyclohexane & $\sigma C_{4} H_{9}$ & & 46 \\
\hline
\end{tabular}

The oxidation of alkylbenzenes and alkylcyclohexanes has already been the subject of several studies. While several work concerning their ignition (e.g. Roubaud et al., 2000, Husson et al., 2012a, Husson et al., 2012b, Darcy et al., 2014 and Nakamura et al., 2014) or flame (e.g. Pousse et al., 2009, Pousse et al., 2010 and Mehl et al., 2015) characteristics were recently published, the detailed low-temperature oxidation chemistry of members of the two previously mentioned families larger than $C_{9}$ has yet not very often been investigated. However a significant improvement in understanding the chemistry involved during fuel low-temperature ignition and oxidation requires the experimental quantification of the wide range of intermediates and products formed during these reactions. As shown in Table 2, a few recent studies of this type already concern detailed analyses of the products formed during the oxidation of $\mathrm{C}_{8}-\mathrm{C}_{12}$ alkylbenzenes and alkylcyclohexanes. Note that all these studies have been performed in jet-stirred reactors (JSRs), except that on $n$-propylbenzene at high pressure which was performed in a shock tube, and that on $n$-butylcyclohexane for which a flow reactor was used. Note that JSR, the type of reactor which was used in the present study, is a well-adapted tool for kinetic studies of fuel low-temperature ignition and oxidation chemistry (Dagaut et al., 2002, Battin- 
Leclerc et al., 2010 and Herbinet and Battin-Leclerc, 2014). This reactor can be modeled by a continuous stirred-tank reactor operated at steady state under well-defined conditions (constant volume, pressure, temperature and space time). Performing simulations with large detailed kinetic models ( 0 dimension problem) is thus possible under these conditions. Another advantage of the JSR is the relatively easy sampling and coupling with analytical methods enabling the quantification of a wide range of species.

Table 2: Summary and conditions of the recent experimental studies of alkylbenzene and alkylcyclohexane oxidation with species analyses found in literature and obtained in this work.

\begin{tabular}{|c|c|c|c|c|c|}
\hline Fuel & Reactor type ${ }^{a}$ & $\mathrm{~T}(\mathrm{~K})$ & $P$ (bar) & $\varphi$ & Reference \\
\hline \multirow{2}{*}{ ethylbenzene } & JSR & $750-1100$ & 1.067 & $0.25-2$ & Husson et al., 2013 \\
\hline & JSR & $750-1100$ & 6 & 1 & This work \\
\hline \multirow{2}{*}{ n-propylbenzene } & JSR & $900-1250$ & 1 & $0.5-1.5$ & Dagaut et al., 2002 \\
\hline & ST & 838-1669 & $25-50$ & $0.5-1.9$ & Gudiyella et al., 2012 \\
\hline \multirow{2}{*}{$n$-butylbenzene } & JSR & $550-1100$ & 1.067 & $0.25-2$ & Husson et al., 2012a \\
\hline & JSR & $550-1150$ & 10 & $0.25-1.5$ & Diévart et al., 2011 \\
\hline$n$-hexylbenzene & JSR & $550-1100$ & 1.067 & 1 & $\begin{array}{c}\text { Battin-Leclerc et al., } 2015 \text { \& } \\
\text { this work }\end{array}$ \\
\hline \multirow{2}{*}{ ethylcyclohexane } & JSR & $500-1100$ & 1.067 & $0.25-2$ & Husson et al., 2012b \\
\hline & JSR & $800 \& 850$ & $1-10$ & 1 & This work \\
\hline n-propylcyclohexane & JSR & $950-1250$ & 1 & $0.5-1.5$ & Ristori et al., 2001 \\
\hline \multirow{3}{*}{ n-butylcyclohexane } & $\mathrm{FR}$ & $600-820$ & 8 & 0.38 & Natelson et al., 2011 \\
\hline & JSR & $500-1100$ & 1.067 & $0.25-2$ & This work \\
\hline & JSR & $800 \& 850$ & $1-10$ & 1 & This work \\
\hline
\end{tabular}

aJSR=Jet-stirred reactor; ST=Shock Tube; and FR=Flow Reactor.

The purpose of the present study was to extend the range of the studies performed in a JSR for alkylbenzenes and alkylcyclohexanes under similar conditions with the objective of comparing the reactivity of species and making relationships between the reactivity and the structure. The effect of the size of the side alkyl chain on the reactivity was investigated for each family. Comparisons were also made for species having the same carbon skeleton but belonging to different families (e.g. ethylbenzene vs. ethylcyclohexane or $n$-butylbenzene vs. $n$-butylcyclohexane). New data obtained in the present study are summarized in Table 2. 


\section{Experimental method}

Experiments were performed using two different apparatuses: one including a jet-stirred reactor working at pressures close to the atmosphere (1.067 bar in the present work) that has already been used for many studies, especially previous ones on alkylbenzenes (Husson et al., 2012a, Husson et al., 2013 and Battin-Leclerc et al., 2015) and ethylcyclohexane (Husson et al., 2012b), and a second one involving a new JSR working at pressures up to 10 bar. Figure 1 displays a diagram of the experimental apparatus used for JSR experiments at pressures above 1 bar. Both spherical fused silica JSRs were designed according to the same rules as those described by Herbinet and Dayma (2013), allowing a perfect missing inside the reactor due to turbulent jets obtained from nozzles as demonstrated by Matras and Villermaux (1973).

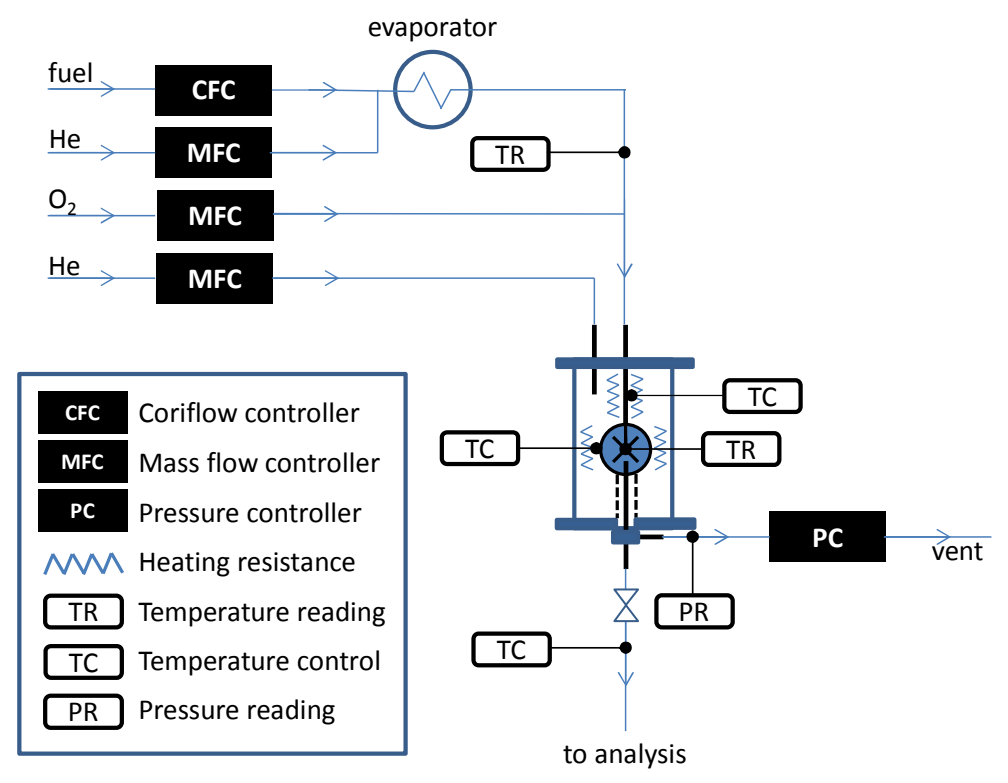

Figure 1: Diagram of the experimental apparatus used to perform experiments at pressures above 1 bar.

Both reactors were preceded by an annular preheating to heat the mixture up to the reaction temperature and to then avoid the formation of important temperature gradients inside the reactor. Due to the use of high dilution levels, temperature gradients inside the reactor were always lower than $5 \mathrm{~K}$. Both reactor and preheating were heated thanks to Thermocoax resistances rolled up around them. The temperature control was achieved with Eurotherm 3216 controllers and type K thermocouples. The reaction temperature (accuracy of $\pm 2 \mathrm{~K}$ ) was measured thanks to another type $\mathrm{K}$ thermocouple located in the intra-annular part of the preheating with its extremity in a glass finger inside the spherical part. 
The main difference between both reactors was the diameter of the sphere which has been lowered from $56 \mathrm{~mm}$ for the atmospheric pressure JSR to $52 \mathrm{~mm}$ for the high pressure one. This reduction has been made in order to decrease the volume of the reactor from $92 \mathrm{~cm}^{3}$ to $74 \mathrm{~cm}^{3}$. This helped decreasing gas flow rates through the reactor (and thus the consumption of reactants and carrier gas) and maintaining the reaction temperature constant despite the exothermicity of the reaction. The decrease of the JSR volume mainly impacted the range of accessible space times ${ }^{1}$ which was slightly moved towards lower values (the range slightly evolves from $1-5 \mathrm{~s}$ to $0.5-4 \mathrm{~s}$ ). In both reactors, all the measurements have been carried out for a constant space time of $2 \mathrm{~s}$.

As it was made from fused silica which could not resist to large pressure differences, the high pressure vessel was included in a steel tank, the pressure of with was made equal to that inside the reactor. The pressure equilibrium was obtained thank holes perforated in the tube downstream of the reactor outlet. An auxiliary helium inlet was used to flush the tank and to prevent the reacted gas mixture from flowing through the outlet tube holes.

Gas flow rates were controlled using Bronkhorst High-Tech mass flow controllers. Oxygen and helium were delivered by Messer. Purities of these two gases were $99.995 \%$ and $99.999 \%$, correspondingly. For liquid fuels, flow rates were measured using a Bronkhorst mini-CORI-FLOW controller coupled to an evaporator. The accuracy in flow rates given by the manufacturer was $\pm 0.5 \%$. Ethylbenzene (purity 299\%), $n$-butylbenzene (>99\%), and $n$-hexylbenzene (>97\%) were provided by Sigma Aldrich. Ethylcyclohexane ( $\geq 99 \%$ ) was provided by Acros Organics. $n$-Butylcyclohexane ( $\geq 99 \%$ ) was obtained from Alfa Aesar.

The outlet of the atmospheric pressure JSR was directly connected to gas chromatographs (GCS) through a transfer line (about $2 \mathrm{~m}$ long) heated at about $453 \mathrm{~K}$ to avoid the condensation of heaviest reaction products. Using a higher temperature was not attempted to avoid further reactions in the transfer line (e.g., decomposition of fragile species, such as hydroperoxides). The sampling of species from the high-pressure reactor was performed using a fused silica sonic microprobe as commonly used in flame experiments (Pousse et al., 2009). The thin extremity of the probe was located inside the reactor and the other extremity of the probe was connected to GC through a heated transfer line. The small hole (with a diameter of about $100 \mu \mathrm{m}$ ) in the thin part of the probe helped maintaining the pressure drop between the reactor and the transfer line operating at a pressure close to the

\footnotetext{
${ }^{1}$ The space time is $\mathrm{\tau}=\mathrm{V} / \mathrm{Q}$, where $\mathrm{V}$ is the reactor volume (which is constant) and $\mathrm{Q}$ is the total gas flow rate through the reactor under the pressure and temperature conditions of the reaction. Two keep the space time constant, the flow rate $Q$ is adjusted in each experiments according to the temperature and the pressure.
} 
atmospheric one. Another benefit of this pressure drop was the freezing of the gas phase reaction during the sampling from the reactor due to the abrupt fall of the temperature.

The analytical procedure has already been described in previous papers (Husson et al., 2012a, Husson et al., 2012b and Husson et al., 2013) and only the main features are repeated here (details about gas chromatography analyses are given in supplemental data). Species were analyzed online using three GCs. The first GC was used for the quantification of oxygen and carbon oxides (separated in a Carbosphere packed column and detected with a thermal conductivity detector). The second one (fitted with a PlotQ capillary column and a flame ionization detector) was used for species from methane to $C_{5}-C_{6}$ species. The third one (fitted with a HP-5 capillary column and a flame ionization detector) was used for molecules with at least 5 carbon atoms. The temperature of the transfer line was set to a maximum of $473 \mathrm{~K}$, but this was not high enough to keep all the reaction products in the gas phase during the study of $n$-hexylbenzene. Amongst the important combustion products which can be expected, formaldehyde $\left(\mathrm{CH}_{2} \mathrm{O}\right)$ and water were not quantified.

Calibrations were performed by injecting standards when available or by using the effective carbon number method (Tranchant et al., 1982) (only applicable with the flame ionization detector) when not available. Maximum relative uncertainty in mole fractions was estimated as $\pm 10 \%$ and the limit of detection for species was about $1 \mathrm{ppm}$ for species analyzed using flame ionization detector and 100 ppm for species analyzed using thermal conductivity detector. Reaction products were identified using a GC (equipped with a PlotQ or an HP5 capillary column) coupled to a mass spectrometer (MS). The mass spectra of most detected reaction products were included in the NIST 08 Mass Spectra Database.

During $n$-hexylbenzene oxidation, it was not possible to quantify neither the initial fuel nor products heavier than ethylbenzene due to a too low volatility and condensation problem in the transfer line between the reactor and the gas chromatographs. However, when the outlet gas was trapped at liquid nitrogen temperature and the content of the trap was afterward analyzed, the formation of the following products were detected by GC-MS, for a reactor temperature of $650 \mathrm{~K}$ : pentanal, methylpentanal, benzaldehyde, 1-, 3- and 4-hexenylbenzenes, the five 1-phenylhexanones, 6-phenylhexanal, diphenylmethane and several benzyl cyclic ethers which could not be more accurately identified due to too low amounts formed; for a reactor temperature of $800 \mathrm{~K}$ : $\alpha$-methylstyrene, 1- and 2-propylbenzene, benzaldehyde, benzeneacetaldehyde, phenol, 3-butenylbenzene, 4-pentenylbenzene, naphthalene, and bibenzyl. During $n$-butylcyclohexane oxidation, a large number of species with a molar mass of $154 \mathrm{~g} / \mathrm{mol}$ had been identified. These 
correspond to cyclic ethers, ketones and aldehydes keeping the same hydrocarbon structure as the reactant. However, contrary to the previous ethylcyclohexane study by Husson et al. (2012b), these important products could not be more accurately identified due to too crowded chromatograms.

Carbon atom balances have been calculated when possible (for $n$-hexylbenzene, the fuel could not be accurately quantified) to check the consistency of experimental results. They were always around $100 \%$ in the high temperature region whatever the equivalence ratio and the pressure. At lowtemperature, they were lower than $100 \%$ by around $5 \%$ because some reaction products were not quantified (e.g., formaldehyde and some oxygenated products with the same skeleton as the reactant). Note that experiments at quasi atmospheric pressure (1.067 bar) were carried out at constant inlet carbon content to enable the comparison of the reactivity of the different fuels (inlet fuel mole fraction of 0.005 for ethylbenzene and ethylcyclohexane, 0.004 for $n$-butylbenzene and $n$-butylcyclohexane, 0.0033 for $n$-hexylbenzene). These comparisons are shown in the three next parts of this paper. After that we discuss the effect of varying the equivalence ratio and the pressure on the reactivity and the formation of products.

\section{Influence of the length of the alkyl chain on alkylbenzene oxidation $(P \sim 1$ bar, $\varphi=1)$}

Figure 2 displays a comparison of mole fraction profiles of the species commonly quantified during the oxidation of the three alkylbenzenes studied at atmospheric pressure under stoichiometric conditions. The influence of equivalence ratio on ethylbenzene and $n$-butylbenzene JSR oxidation was already described in details (Husson et al., 2012a and Husson et al., 2013). An excel file providing the experimental mole fractions of all the products analyzed during the oxidation of $n$-hexylbenzene is given as supplementary material. Note that many aromatics were observed during the oxidation of ethylbenzene and $n$-butylbenzene (only benzene, toluene and styrene are shown in Figure 2). Due to condensation trouble, very few aromatics could be accurately quantified during the oxidation of $n$-hexylbenzene and only data for benzene, toluene and styrene are presented in this work.

Only the experimental conversions of ethylbenzene $\left(\varphi C_{2} H_{5}\right)$ and $n$-butylbenzene $\left(\varphi C_{4} H_{9}\right)$ are displayed in Figure 2a since it was not possible to quantify $n$-hexylbenzene $\left(\varphi C_{6} H_{13}\right)$, as explained previously. Experiments showed that $\varphi C_{2} H_{5}$ was not reactive below $750 \mathrm{~K}$ whereas $\varphi C_{4} H_{9}$ had a maximum conversion of $13 \%$ at $650 \mathrm{~K}$ (Figure 2a). The two species had similar conversion in the high temperature region (above $775 \mathrm{~K}$ ). 


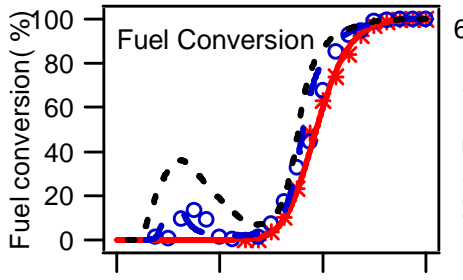

(a) $\begin{array}{llll}500 & 700 & 900 & 1100\end{array}$

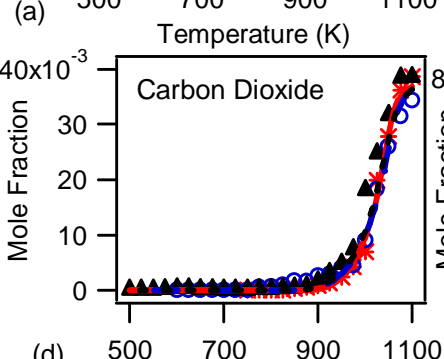

(d) $\quad 500 \quad 700 \quad 900 \quad 1100$

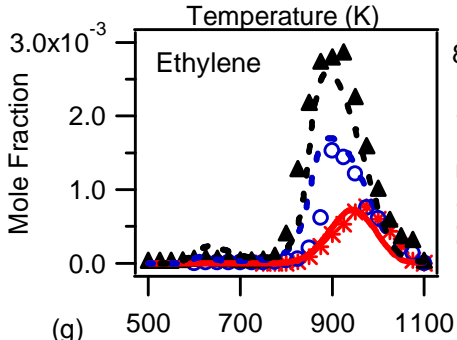

$(\mathrm{g})$

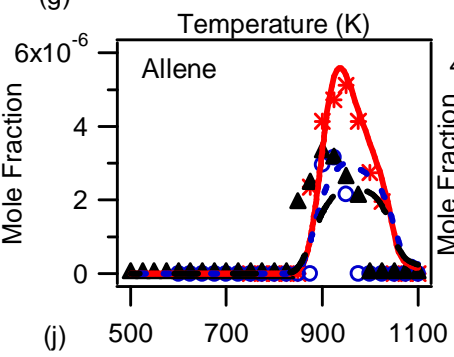

(j) $500 \quad 700 \quad 900 \quad 1100$

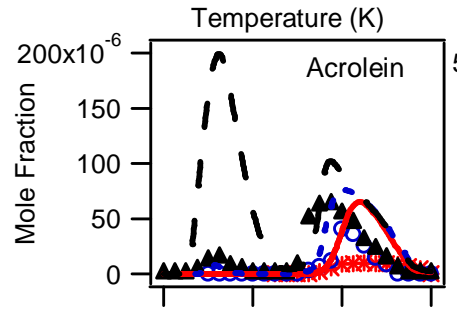

(m) $\quad 500 \quad 700 \quad 900 \quad 1100$

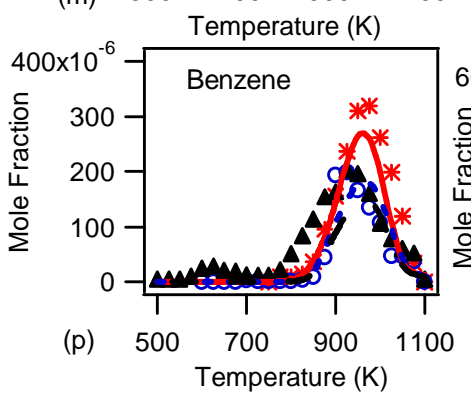

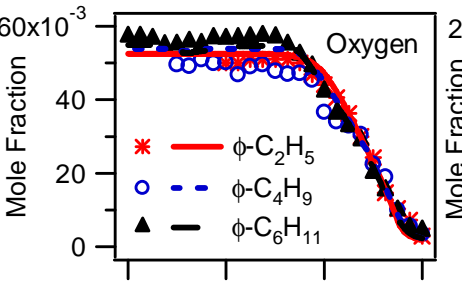

(b)
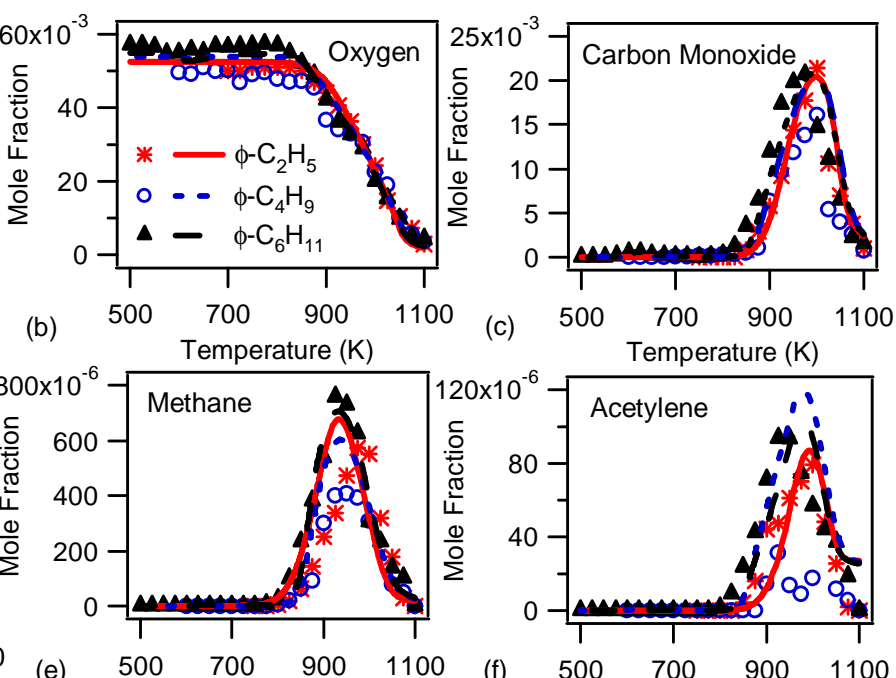

(c)

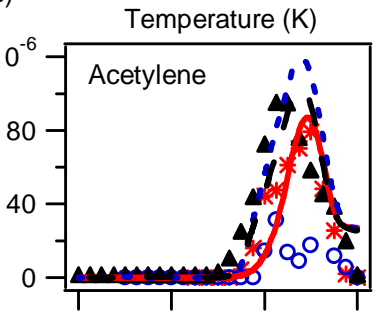

(e) 500 Temperature (K)
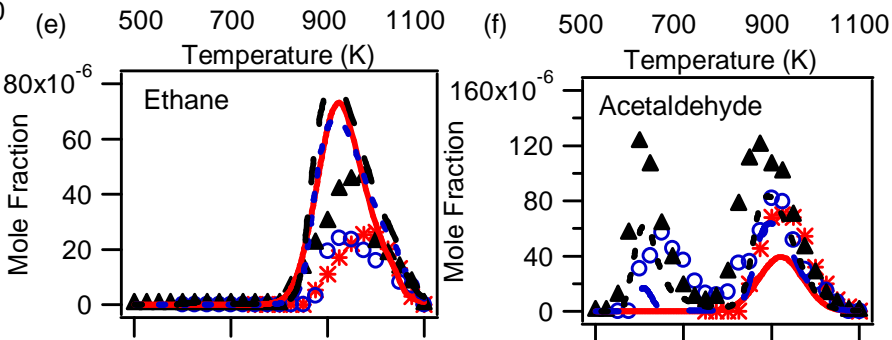

(h) $500 \quad 700 \quad 900 \quad 1100$

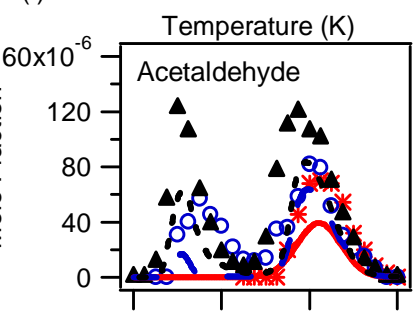

(i) $\quad 500 \quad 700 \quad 900 \quad 1100$
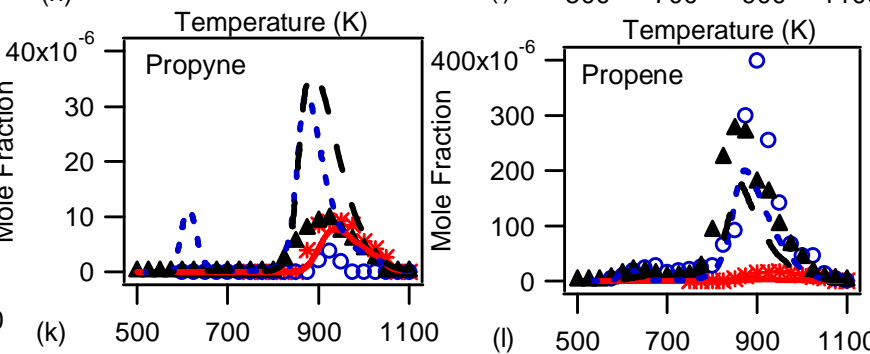

(I) $\quad 500 \quad 700 \quad 900 \quad 1100$
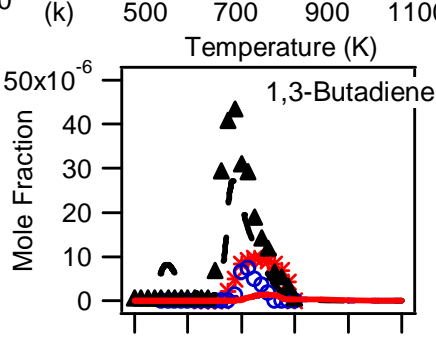

(n) 500700900110013001500
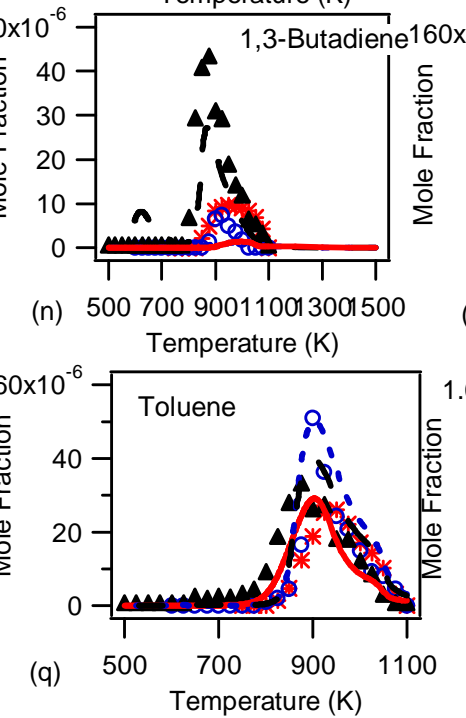

(o) $500 \quad 700 \quad 900 \quad 1100$

Temperature $(\mathrm{K})$

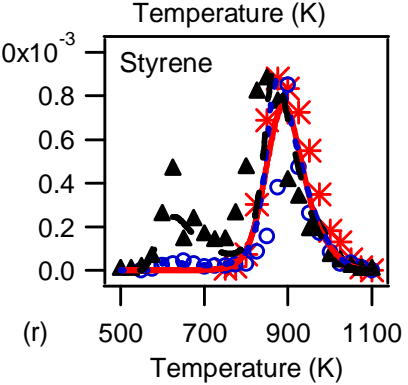

Figure 2: Oxidation of alkylbenzenes in a jet-stirred reactor at 1.067 bar. Evolution of the conversion and product mole fractions with temperature (inlet fuel carbon content constant: $x_{\varphi C_{2} H_{5}}=0.005$ (Husson at al., 2013), $x_{\varphi C_{4} H_{9}}=0.004$ (Husson at al., 2012a), $x_{\varphi C_{6} H_{13}}=0.0033, \tau=2 \mathrm{~s} ; \varphi=1$ ). Symbols are experimental data and lines data computed with literature models (Battin-Leclerc et al., 2015). 
Due to a complex, but well-known mechanism (Battin-Leclerc, 2008 and Zádor et al., 2011), the temperature evolution of the JSR reactivity of most hydrocarbon containing a $C_{3+}$ alkyl chain exhibits two distinct zones: one below about $800 \mathrm{~K}$ where low-temperature chemistry is determinant and one above that is due to high-temperature reactions (Herbinet and Battin-Leclerc, 2014). These two zones are separated by an intermediate zone, usually called the "negative coefficient temperature zone", in which a temperature increase causes a decrease of the reactivity. Gas-phase oxidation reactions are known to be mostly chain reactions involving free-radicals, the most important chain carrier being the hydroxyl radical $(\mathrm{OH} \bullet)$. Figure 3 summarizes the main reactions usually considered to explain the oxidation of alkylbenzenes $\left(>C_{8}\right)$ and alkylcyclohexanes.

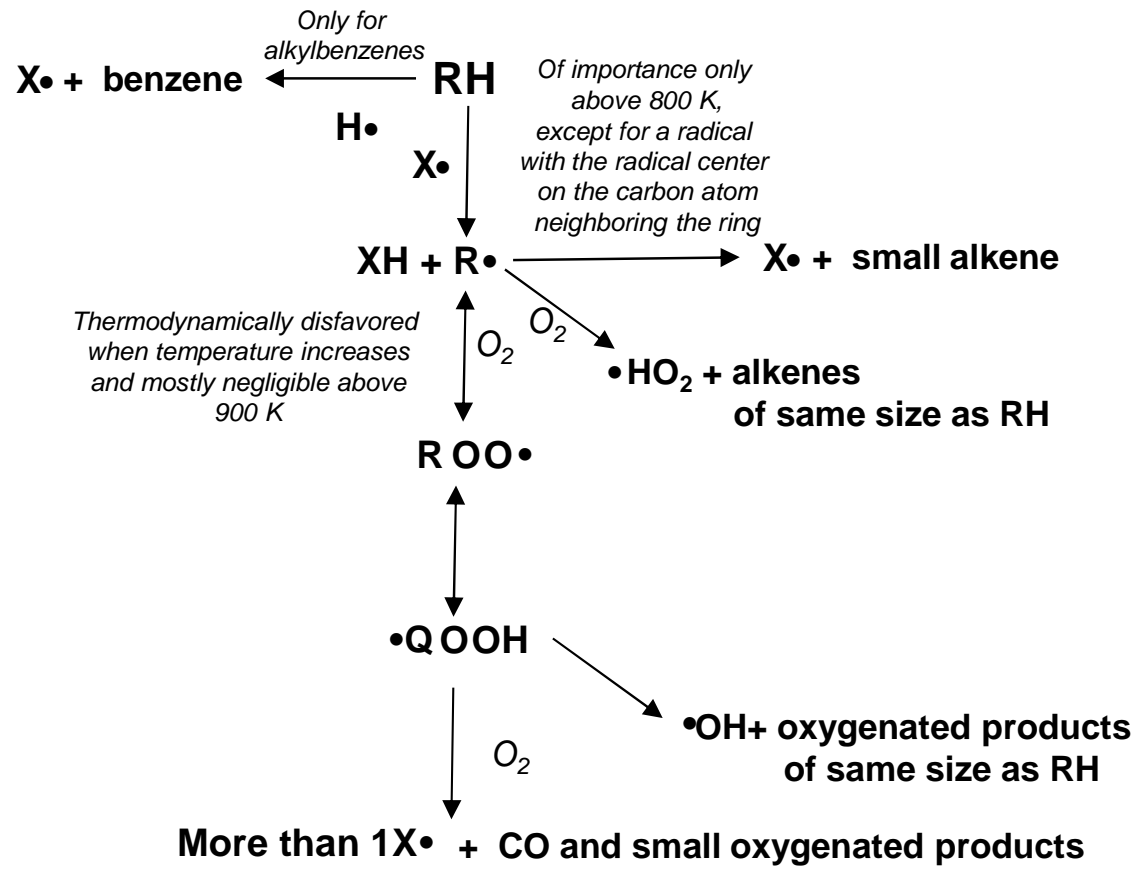

Figure 3: Simplified general scheme of the oxidation of alkylbenzenes $\left(>C_{8}\right)$ and alkylcyclohexanes

$(\mathrm{RH}) . \mathrm{X} \bullet$ represents any free-radical.

At low-temperatures, the oxidation chemistry is controlled by the addition to oxygen of the freeradicals $(\mathrm{R} \bullet)$ obtained by $\mathrm{H}$-atom abstractions from the reactant $(\mathrm{RH})$ to form peroxy radicals $(\mathrm{ROO} \bullet)$. The subsequent reactions of these peroxy radicals are a source of a wide range of oxygenated products, such as $\mathrm{CO}$, aldehydes, ketones and cyclic ethers. At high-temperatures, the previously mentioned R• radicals rather decompose to yield smaller radicals and unsaturated hydrocarbons (ethylene, propene...). This is a source of potential soot precursors. 
Literature detailed kinetic models containing the above described chemistry and automatically generated using EXGAS software (Battin-Leclerc et al., 2015) have been used to compute the fuel conversion and product mole fractions (Figure 2). The agreement between experimental and computed data is overall satisfactory. The over-estimation of mole fractions of acrolein at lowtemperature for $\varphi C_{6} H_{13}$ is due to the lumping strategy (Biet et al., 2008) used in the generation of the secondary mechanism for the decomposition of radicals obtained through $\mathrm{H}$-atom abstractions of cyclic ethers which are abundant for $\varphi C_{6} H_{13}$. A similar observation can be made for the over-estimation of propyne mole fractions at low- and high-temperature for $\varphi C_{4} H_{9}$ and at high-temperature for $\varphi C_{6} H_{13}$ (the incriminated reaction class is the decomposition of radicals obtained by $\mathrm{H}$-atom abstraction from unsaturated alkenyl benzene species).

In order to experimentally compare the reactivity of the three fuels in the low-temperature region, it is possible to compare the mole fraction profiles of typical low-temperature reaction products, such as CO (Figure 2c) and acetaldehyde (Figure 2i). CO maximum mole fraction was $74 \mathrm{ppm}$ for $n$ butylbenzene against $503 \mathrm{ppm}$ for $\varphi C_{6} H_{13}$ clearly proving that the heavier the fuel, the higher the reactivity. The reactivity differences predicted using literature models (Battin-Leclerc et al., 2015) well agrees with this experimental observation. Another interesting difference is the significant shift of the temperature of maximum reactivity in the low temperature region when the size of the side alkyl chain increases. This maximum was obtained at $650 \mathrm{~K}$ for $\varphi C_{4} H_{9}$ and at $625 \mathrm{~K}$ for $\varphi C_{6} H_{13}$. Note that this feature is not well reproduced by models as predicted maximum mole fractions are all obtained at the same temperature. The higher low-temperature reactivity of $\varphi C_{6} H_{13}$ compared to $\varphi C_{4} H_{9}$ is also indicated by the larger formation of acetaldehyde (Figure 2i), acrolein (Figure 2m), 1-butene (Figure 2o), benzene (Figure 2p), and styrene (Figure $2 r$ ). Note that with $n$-hexylbenzene, a noticeable formation of styrene was obtained at $600 \mathrm{~K}$, clearly proving a significant reactivity due to alkyl chain reactions in this temperature range. According to the kinetic analysis performed at $650 \mathrm{~K}$ using literature models (Battin-Leclerc et al., 2015), styrene mainly come from the decomposition of radicals obtained from cyclic ethers (with a phenyl group) formed in the low-temperature oxidation of $\varphi C_{6} H_{13}$. The benzene formation is mainly due to ipso-additions ${ }^{2}$ of $\mathrm{H}$-atoms (see Figure 3 ). According to models, at $625 \mathrm{~K}$, for $\varphi C_{6} H_{13}$, benzene mainly comes from the ipso-addition of $\mathrm{H}$-atom to fuel $(\approx 88 \%$ of its formation) and to a lesser extent from the ipso-additions of $\mathrm{H}$-atom to benzaldehyde $(\approx 7 \%)$ and to styrene $(\approx 3 \%)$. Like all radical concentrations, that of $\mathrm{H}$-atoms increases with increasing reactivity, explaining the largest benzene formation below $800 \mathrm{~K}$ with $\varphi C_{6} H_{13}$ as fuel (according to kinetic

\footnotetext{
${ }^{2}$ Ipso-addition reactions consist in the substitution of the alkyl chain $(-R)$ by the atom or the radical $(X \bullet)$ involved in the reaction $\varphi-R+X \bullet \rightleftarrows \varphi-X+R \bullet$.
} 
analyses, $\mathrm{H}$-atom mole fractions at $675 \mathrm{~K}$ are $3.4 \times 10^{-11}$ and $1.35 \times 10^{-10}$ for $\varphi C_{4} H_{9}$ and $\varphi C_{6} H_{13}$, respectively).

Supporting the fact that hydrocarbon low-temperature reactivity is responsible for the first steps leading to auto-ignition, the increase of the low-temperature reactivity with the alkyl chain size is in good agreement with the cetane number variation shown in Table 1. This trend can be explained by two kinetic features of alkyl-benzene species: the formation of radicals by $\mathrm{H}$-atom abstractions from the ring which is negligible, and that from the carbon atom neighboring the ring (H-atoms in the benzylic position) which is significantly favored due to a lower bond energy, but leads to radicals which hardly react by addition with oxygen molecule. These two features hinder the low-temperature reactivity for short size compounds. As an example, at $625 \mathrm{~K}$, simulations indicate that abstractions of the two benzylic $\mathrm{H}$-atoms represent about $37 \%$ of all $\mathrm{H}$-atom abstractions for $\varphi C_{6} H_{13}$, and $44 \%$ for $\varphi C_{4} H_{9}$ (ethyl-benzene is not reactive under these conditions) respectively, showing that the specificities due to features of this particular type of $\mathrm{H}$-atom are progressively diminishing with increasing alkyl chain.

According to the mole fraction profile of carbon dioxide (Figure 3d), the three alkylbenzenes have about the same reactivity in the high-temperature region (above $775 \mathrm{~K}$ ). This is well predicted by data computed using literature models. Some differences are however observed in the mole fraction profiles of some reaction products in this temperature region despite the similarity in reactivity. These differences are due to the structure of initial fuels, especially to the number of carbon atoms in the side alkyl-chain. As a first example, mole fractions of $C_{4}$ species (1,3-butadiene in Figure $2 \mathrm{n}$ and 1-butene in Figure 2o) were significantly larger in the case of $\varphi C_{6} H_{13}$ as this fuel includes a longer alkyl-chain to be broken. As an example, at $850 \mathrm{~K}$, simulations indicate that for $\varphi C_{6} H_{13}$, 1-butene derives from the decomposition of 3-hexyl (23\%), 4-hexyl-benzene (35\%) and 1-butyl (40\%) radicals. 3-hexyl radicals are formed by the isomerization of 1-hexyl radicals which are mainly produced from fuel ipso-additions. 4-hexyl-benzene radicals are directly formed from the fuel through $\mathrm{H}$-atom abstractions. 1-butyl radicals are obtained from the decomposition of the 1-hexyl-benzene radicals which are formed via abstractions of benzylic $\mathrm{H}$-atoms from the fuel.

The position of the maximum mole fractions of reaction products in the high-temperature region is shifted towards lower temperatures when the size of the chain increases. For acetaldehyde, the experimental maximum is located at $925 \mathrm{~K}$ for $\varphi C_{2} H_{5}$, at $900 \mathrm{~K}$ for $\varphi C_{4} H_{9}$ and at $875 \mathrm{~K}$ for $\varphi C_{6} H_{13}$. This feature is overall well predicted by models as it can be spotted for ethylene (Figure $2 \mathrm{~d}$ ). As far as soot precursors are concerned, the formation of allene (Figure $2 \mathrm{j}$ ) and benzene (Figure $2 p$ ) was the 
largest for ethylbenzene, while that of toluene (Figure $2 q$ ) and styrene (Figure $2 r$ ) was similar for the three reactants. According to the kinetic analysis, the difference in benzene mole fractions is explained by the slight difference in the reactivity between the three fuels in the temperature range 850-950 K. Under these conditions, the conversion of ethylbenzene is slightly lower than that of the two other fuels which favors ipso-additions (the concentrations of $\mathrm{H}$-atoms are very similar for the three fuels according to rate of production analysis). The formation of aldehydes, acetaldehyde (Figure 2i) and acrolein (Figure $2 \mathrm{~m}$ ), was the largest for $\varphi C_{6} H_{13}$ in both temperature zones.

Note that only products measured for the three reactants are displayed in Figure 2, but as shown in (Husson et al., 2012a and Husson et al., 2013), oxygenated aromatic products common to $\varphi C_{2} H_{5}$ and $\varphi \mathrm{C}_{4} \mathrm{H}_{9}$ (phenol, benzaldehyde, benzofuran, benzeneacetaldehyde, acetophenone, cresols) and aromatic hydrocarbons specific to $\varphi C_{4} H_{9}$ (1-propenylbenzene, 1-, 2-, 3-butenylbenzenes, indane, indene, tetralin, 1,4-dihydronaphthalene, naphthalene) were also quantified.

\section{Influence of the length of the alkyl chain on alkylcyclohexane oxidation ( $p$ 1 bar,}

\section{$\varphi=0.25,1$, and 2$)$}

Figure 4 presents a comparison of some of the experimental products obtained during the oxidation study of ethylcyclohexane $\left(\sigma C_{2} H_{5}\right)$ and $n$-butylcyclohexane $\left(\sigma C_{4} H_{9}\right)$ at atmospheric pressure at three equivalence ratios, $0.25,1$ and 2 . Previous data for the oxidation of cyclohexane obtained under the same conditions (Serinyel et al., 2013) are also presented for stoichiometric mixtures. More products produced from $\sigma C_{4} H_{9}$ are described further in the text. An excel file providing the experimental mole fractions of all the products analyzed during the oxidation of $n$-butylcyclohexane is given as supplementary material.

The evolution of the conversion of the two fuels with temperature is presented in Figures 4a-c. Both species are reactive in the low-temperature region with a large conversion (around 50\%) obtained at $625 \mathrm{~K}$ at $\varphi=1$ (Figure $4 \mathrm{~b}$ ). Mole fraction profiles of $\mathrm{CO}$ (Figures $4 \mathrm{~d}-\mathrm{f}$ ) and $\mathrm{CO}_{2}$ (Figures $4 \mathrm{~g}-\mathrm{i}$ ) are very similar for the two fuels. Ethylene (Figures $4 \mathrm{j}-\mathrm{I}$ ) and acetaldehyde (Figures $4 \mathrm{~m}-\mathrm{O}$ ) mole fraction profiles have also a similar shape. There are more differences in mole fraction profiles of benzene (Figures $4 p-$ r) and cyclohexene (Figures 4s-u). Benzene and cyclohexene are mainly formed in the high temperature zone. In this zone, their mole fractions are larger for ethylbenzene at all studied $\varphi$. 

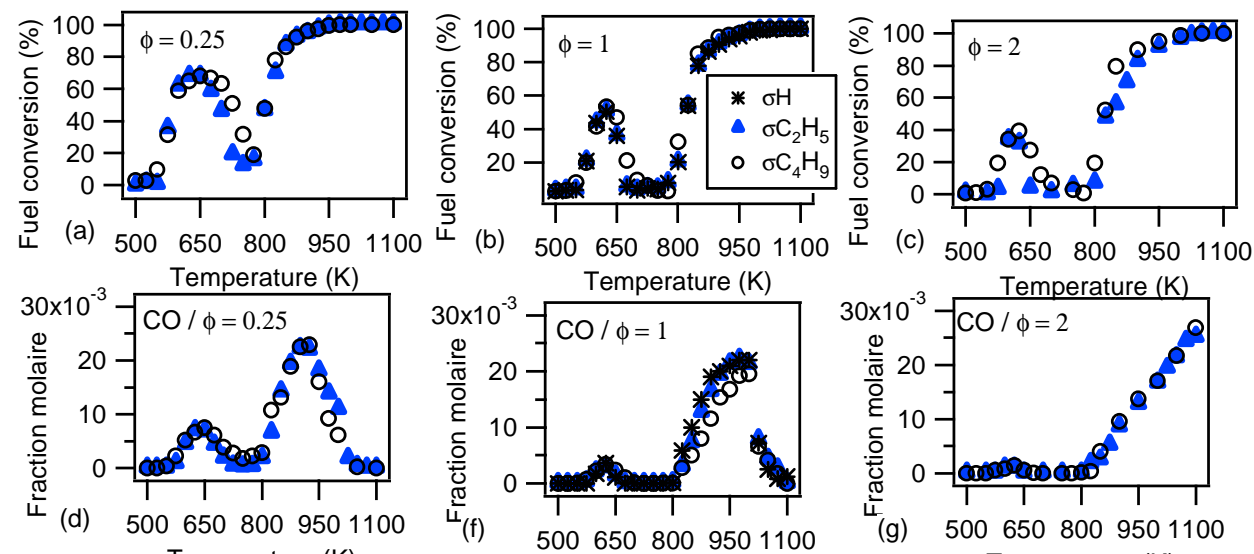

(c) $\begin{array}{lllll}500 & 650 & 800 & 950 & 1100\end{array}$
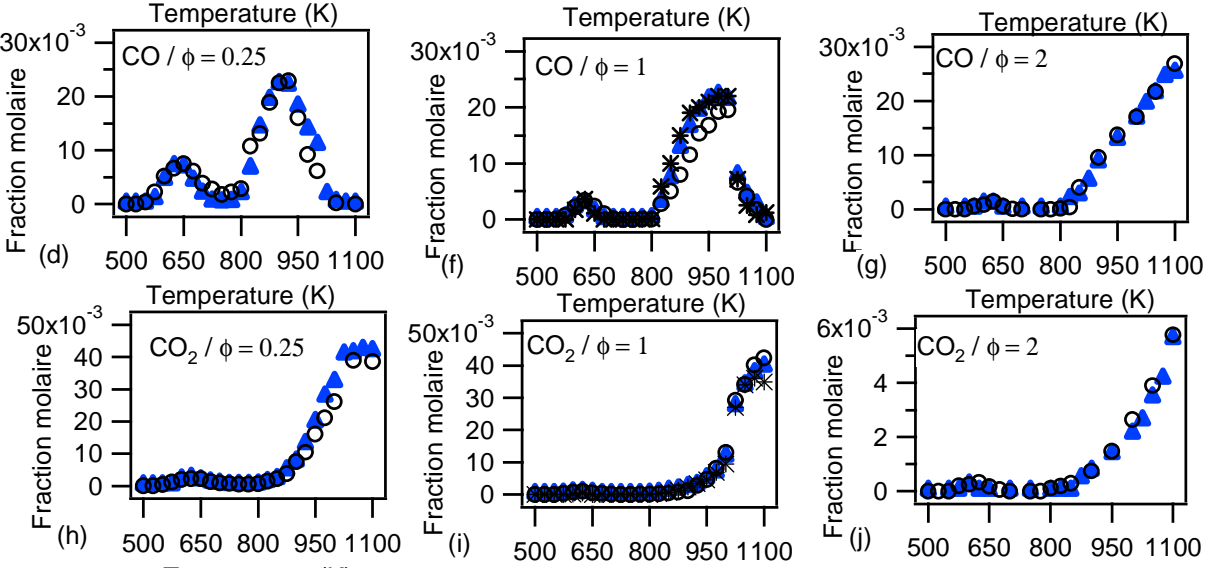

(g) 5006508009501100
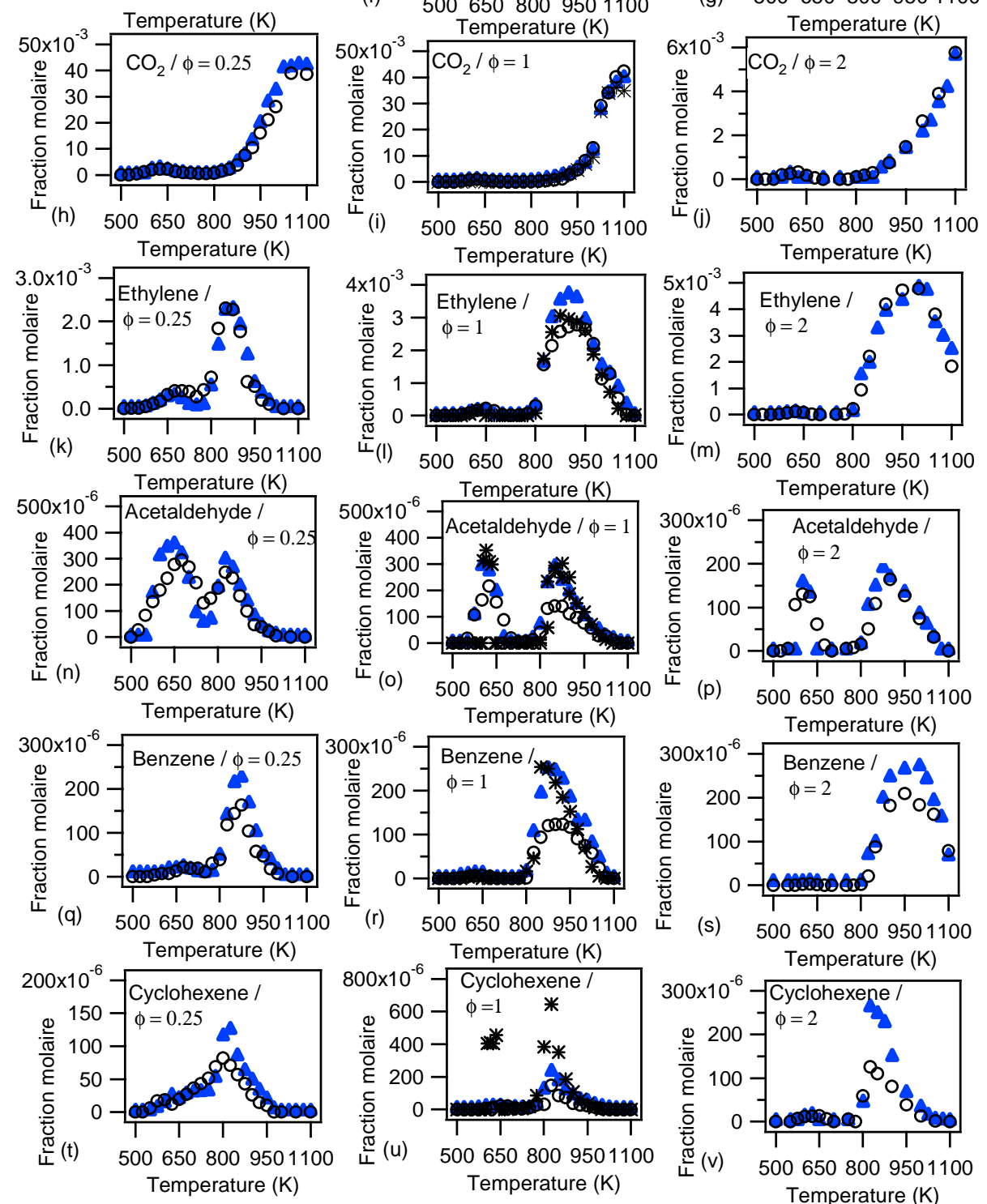

Figure 4: Oxidation of alkylcyclohexanes in a jet-stirred reactor at 1.067 bar. Evolution of conversion and product mole fractions with temperature (inlet fuel carbon content constant: $x_{\sigma C_{2} H_{5}}=5.10^{-3}$ (Husson et al., 2013), $x_{\sigma C_{4} H_{9}}=4.10^{-3}, \tau=2 \mathrm{~s}$ ) and comparison with cyclohexane results under the same conditions $\left(x_{\sigma H}=6.67 .10^{-3}\right)$ (Serinyel et al., 2013). 
The very small differences obtained in fuel conversion and product formations between $\sigma C_{2} H_{5}$ and $\sigma C_{4} H_{9}$ well agree with both compounds having almost the same cetane number. However when comparing with cyclohexane it can be seen that very similar results have also been obtained for this $\mathrm{C}_{6}$ compound while its cetane number (15) is notably lower than that of the two alkylcyclohexanes studied here $(\approx 45)$. This proves that the variation of the cetane number of a fuel is not fully correlated with its low-temperature reactivity measured in an isobaric, isothermal, isochoric continuous flow reactor.

One major difference between cyclohexane and larger alkyl-cyclohexanes was the maximum mole fraction of cyclohexene obtained. It was about 10 times larger for cyclohexane than those obtained with the two other compounds. According to the kinetic analysis performed using a literature model (Serinyel et al., 2013), the routes of formation of this species depend on the temperature range. At low-temperatures (e.g., $625 \mathrm{~K}$ ), it is mainly formed through the reaction of the cyclohexyl radical with oxygen yielding cyclohexene $+\mathrm{HO}_{2} \bullet(\approx 71 \%$ of its formation $)$ and from the direct elimination of $\mathrm{HO}_{2} \bullet$ radicals from the peroxy-cyclohexyl radical which is obtained through the addition of the cyclohexyl radical to $\mathrm{O}_{2}(\approx 28 \%)$. At higher temperatures (e.g., $\left.825 \mathrm{~K}\right)$, a third pathway adds to the two others: this is the decomposition by $\beta$-scission of the cyclohexyl radical $(\approx 26 \%)$.

The direct elimination from the peroxy-cyclohexyl radical is only $10 \%$ and the reaction with $\mathrm{O}_{2}$ to cyclohexene $+\mathrm{HO}_{2} \bullet$ is $64 \%$. For both alkylcyclohexanes, cyclohexene cannot be produced directly from reactions of fuel radicals with oxygen such as for cyclohexane. Cyclohexene can only be produced by $\mathrm{C}-\mathrm{C}$ bond breaking decompositions of fuel radicals. Thus cyclohexene is mainly formed at high temperatures as it was experimentally observed as is shown in Figures $4 \mathrm{t}-\mathrm{v}$. Unfortunately the existing literature models for ethyl- and $n$-butyl-cyclohexanes (Wang et al., 2010) do not contain the specific chemistry which is necessary to obtain accurate low-temperature predictions. However according to the rate of production analysis performed using this last model at $825 \mathrm{~K}$ for ethyl-cyclohexane, cyclohexene is mainly formed from the reaction of decomposition by $\beta$-scission of one of the fuel radical called $\mathrm{C} 2 \mathrm{H} 5 \mathrm{~S} 2 \mathrm{XcC} 6 \mathrm{H} 10$ with the radical center on one of the two carbon atoms neighboring the only tertiary one.

Mole fractions of cyclohexene obtained during cyclohexane oxidation have been compared to mole fractions of unsaturated hydrocarbons with the same skeleton as the fuel for the two alkylcyclohexanes. Figure 5 presents the temperature evolution of sum of the mole fraction of unsaturated hydrocarbons of the same size as the fuel for cyclohexane (cyclohexene) (Serinyel et al., 2013), ethylcyclohexane (1-, 2-, 3-ethylcyclohexenes, vinylcyclohexene (Husson et al., 2012b)) and 
$n$-butylcyclohexane (1- and 4-butylcyclohexenes). This figure shows that total mole fractions are of the same magnitude order over the whole temperature range with slightly larger mole fractions when cyclohexane is studied. These differences in unsaturated fuel derived product could indicate that fuel radicals with a side alkyl chain prefer adding to $\mathrm{O}_{2}$ and isomerize to hydroperoxy radicals than reacting with $\mathrm{O}_{2}$ to give unsaturated molecules $+\mathrm{HO}_{2}$. Note that it would be interesting to compare these data with data for methyl-cyclohexane which as a short alkyl chain (one carbon atom) to see if it makes a difference with cyclohexane or with larger alkyl-benzenes.

As stated earlier, to our knowledge, no detailed kinetic model is able to reproduce the lowtemperature oxidation of $\mathrm{C}_{3+}$ alkylcyclohexanes has yet been developed. The presence of the ring and of the alkyl chain makes that many isomerizations have to be considered for the radicals produced by the addition to oxygen of radicals obtained by $\mathrm{H}$-atom abstractions from the fuel, with the kinetic data of these isomerizations not straightforward to estimate using simple correlations due to the presence of the ring.

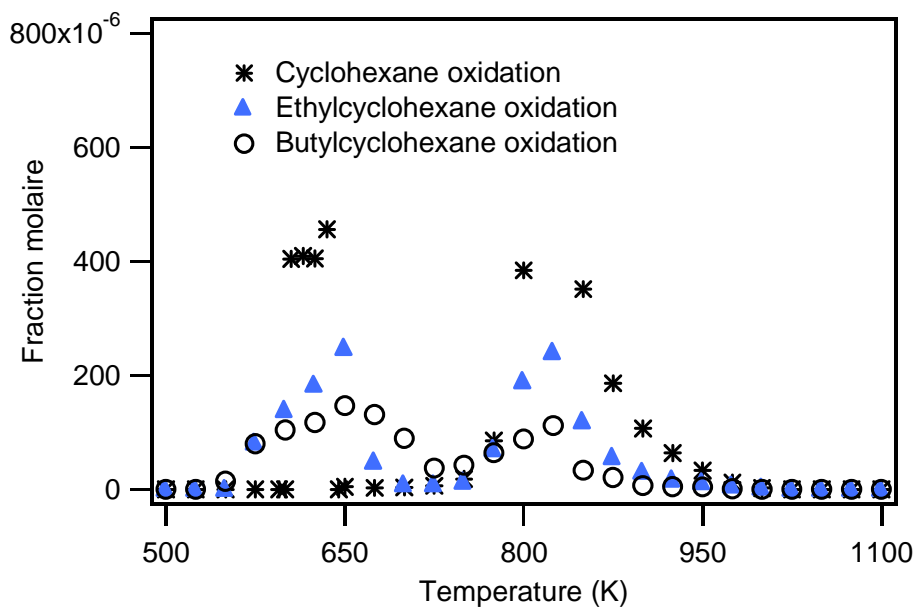

Figure 5: Oxidation of alkylcyclohexanes in a jet-stirred reactor at 1.067 bar. Evolution of the mole fractions of mono-unsaturated hydrocarbons of the same size as the reactant with temperature $\left(x_{\sigma C_{2} H_{5}}=0.005\right.$ (Husson et al., 2012b), $\left.x_{\sigma C_{4} H_{9}}=0.004, \tau=2 \mathrm{~s}\right)$ and comparison with cyclohexane results under the same conditions $\left(x_{\sigma H}=0.00667\right)$ (Serinyel et al., 2013)).

\section{Comparison of reactivity and product formation between alkylbenzenes and alkylcyclohexanes of the same size $(P \sim 1$ bar, $\varphi=1)$}

Figure 6 displays a comparison of the fuel conversion and the mole fraction of some products obtained during the oxidation of alkylbenzenes and alkylcyclohexanes of the same size at atmospheric pressure for stoichiometric mixtures. Fuel conversion is shown in Figures $6 \mathrm{a}$ and b. Ethylbenzene $\left(\varphi \mathrm{C}_{2} \mathrm{H}_{5}\right)$ was 
not reactive in the low-temperature region, whereas ethylcyclohexane $\left(\sigma \mathrm{C}_{2} \mathrm{H}_{5}\right)$ had a maximum conversion of about $50 \%$ at $625 \mathrm{~K}$ (Figure 6a). Differences were also observed in the high-temperature region: the reactivity started increasing at the same temperature (around $775 \mathrm{~K}$ ) for both $\mathrm{C}_{8}$ fuels, but above this temperature, $\varphi C_{2} H_{5}$ was less reactive than $\sigma C_{2} H_{5}$ (the conversion of $\varphi C_{2} H_{5}$ increased more slowly). While $n$-butylbenzene $\left(\varphi C_{4} H_{9}\right)$ was reactive in the low-temperature region, it started to react only around $675 \mathrm{~K}$ against $550 \mathrm{~K}$ for $n$-butylcyclohexane $\left(\sigma C_{4} H_{9}\right)$. Another difference was the position of the maximum of conversion in the low-temperature region: it is $625 \mathrm{~K}$ for $\sigma C_{4} H_{9}$ and $650 \mathrm{~K}$ for $\varphi C_{4} H_{9}$ (Figure 6b). In the high-temperature region, $\varphi C_{4} H_{9}$ was less reactive than $\sigma C_{4} H_{9}$. The significant difference of low-temperature reactivity between alkylbenzenes and alkylcyclohexanes is fully consistent with the cetane number differences shown in Table 1.

An important high-temperature product, ethylene, was formed in the largest amounts for alkylcyclohexanes as shown in Figure $6 c$ and $d$. However the relative difference decreases in the case of $\sigma C_{4} H_{9}$ and $\varphi C_{4} H_{9}$. This is due to the larger side alkyl-chain, which yields radicals which more easily decompose through $\mathrm{C}-\mathrm{C}$ bond breaking to give ethylene in $\varphi C_{4} H_{9}$.

An important low-temperature product, acetaldehyde was about 4 times more produced at $650 \mathrm{~K}$ for $\sigma C_{4} H_{9}$ than for $\varphi C_{4} H_{9}$ as shown in Figure $6 \mathrm{e}$ and $\mathrm{f}$. This is due to the larger reactivity of the alkylcyclohexanes, for which the radicals obtained by $\mathrm{H}$-atom abstractions from the fuel easily react by addition to oxygen molecule yielding a wide range of oxygenated products.

The profile of the sum of the mole fraction of mono-aromatic compounds (benzene, toluene, styrene) is compared in Figures $6 \mathrm{~g}$ and $\mathrm{h}$. These compounds are considered as important soot precursors. Their formation was significantly favored for alkylbenzenes, the structure of which already includes the aromatic ring which is hardly decomposed during oxidation reactions, especially under the conditions of this study. In models, benzene is considered to react by abstractions of aromatic $\mathrm{H}$-atoms to give the phenyl radical. This radical can react with oxygen though a complex reaction yielding carbon monoxide and a cyclic $C_{5}$ radical. However benzene can be considered as mostly unreactive below $900 \mathrm{~K}$, even in presence of a more reactive fuel, such $n$-decane (cetane number=77) (Herbinet et al., 2013). 

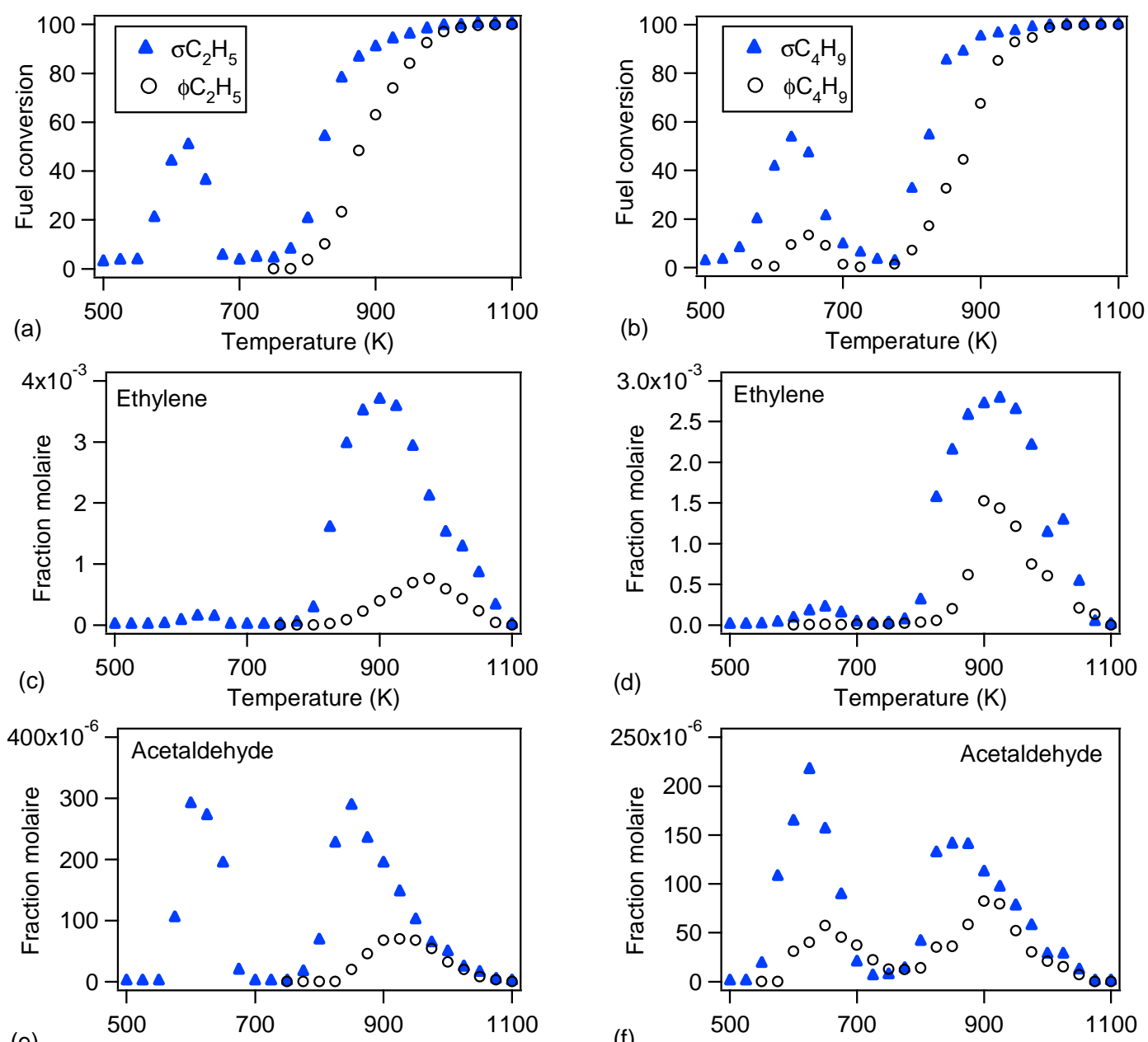

(e)

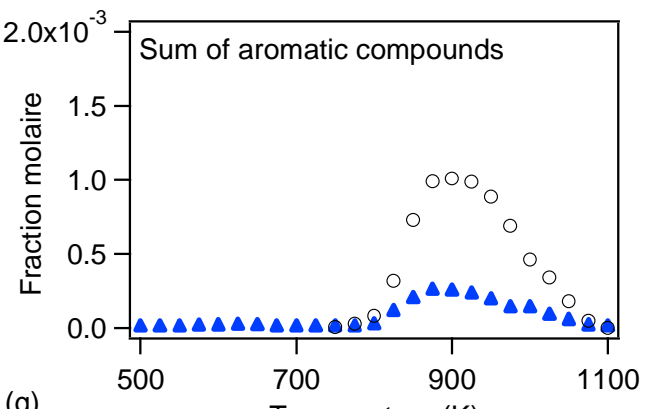

(g)

Temperature (K)

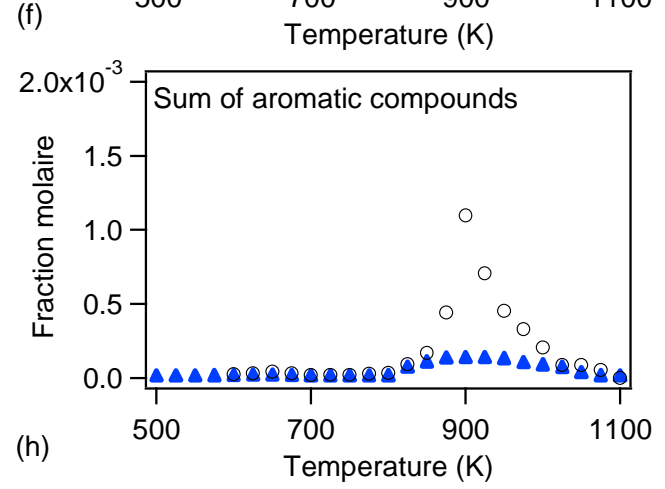

Figure 6: Comparison of the oxidation of ethylbenzene and ethylcyclohexane (left panels) and of $n$-butylbenzene and $n$-butylcyclohexane (right panels). Evolution of the conversion and product mole fractions with temperature $\left(x_{C_{8}}=5.10^{-3}, x_{C_{10}}=4.10^{-3}, \tau=2 \mathrm{~s}, \varphi=1, P=1.067\right.$ bar $)$.

\section{Influence of the equivalence ratio on reactivity and product formation}

The oxidation of ethyl-cyclohexane and $n$-butylcyclohexane are good examples to illustrate the effects of equivalence ratio on the product formation. Similar trends have been seen for the other compounds studied, especially in the high-temperature region. Behaviors can be different in the low-temperature region due to the specific chemistry occurring at these temperatures. Figure 4 and Figure 7 present 
the evolution the fuel conversion and of the mole fractions of important products at three equivalence ratios: $0.25,1$ and 2 .

Whereas conversion profiles obtained for cyclohexane, ethyl-cyclohexane and $n$-butyl-cyclohexane were very similar for a given equivalence ratio (Figures $4 a-c$ ), the equivalence ratio had a large influence on the reactivity at low temperatures. The maximum conversion increased from about $35 \%$ at $\varphi=2$ to about $50 \%$ at $\varphi=1$, and to about $65 \%$ at $\varphi=0.25$. The temperature of the maximum conversion remained in the range $625-650 \mathrm{~K}$ whatever the equivalence ratio. Under fuel lean conditions $(\varphi=0.25)$, the reactivity did not go back down to zero as it is observed for stoichiometric and rich conditions $(\varphi=2)$. The change in equivalence ratio did not cause any significant change in the reactivity in the hightemperature region (Figures $4 a-c$ ).

As shown in Figure 7 ( $n$-butylcyclohexane data), the formation of hydrocarbons was notably favored under rich conditions in the high-temperature zone. This is especially the case of methane (Figure 7a), ethylene (Figure 7b), benzene (Figure 7l) and species known to be precursors of this aromatic species, such as acetylene (Figure 7d) and 1,3-butadiene (Figure 7f). The only exception is 4-butylcyclohexene (the most abundant butylcyclohexene isomer, Figure 7k), the formation of which is significantly favored under lean conditions. Note the particular shape of the mole fraction profile of this species under these conditions: a maximum can be seen at a temperature located in the transition area between the high- and low-temperature zones. This confirms that this type of products has a particular formation pathway favored in presence of high oxygen amounts as explained previously.

In the low-temperature region, mole fractions of oxygenated species were larger under lean conditions. This was the case for $\mathrm{CO}$ (Figures $4 \mathrm{~d}-\mathrm{f}$ ), $\mathrm{CO}_{2}$ (Figures $4 \mathrm{~g}$ and $\mathrm{i}$ ), acetaldehyde (Figure $7 \mathrm{~g}$ ), propanal (Figure 7i), acrolein (Figure 7h) and cyclohexanone (Figure 7j) for example. However mole fractions cannot be used to catch the actual influence of equivalence ratio on the oxidation chemistry in the low-temperature region as there are strong differences in fuel conversion. Thus carbon product selectivities were calculated for the main reaction products detected during the ethylcyclohexane oxidation study. 

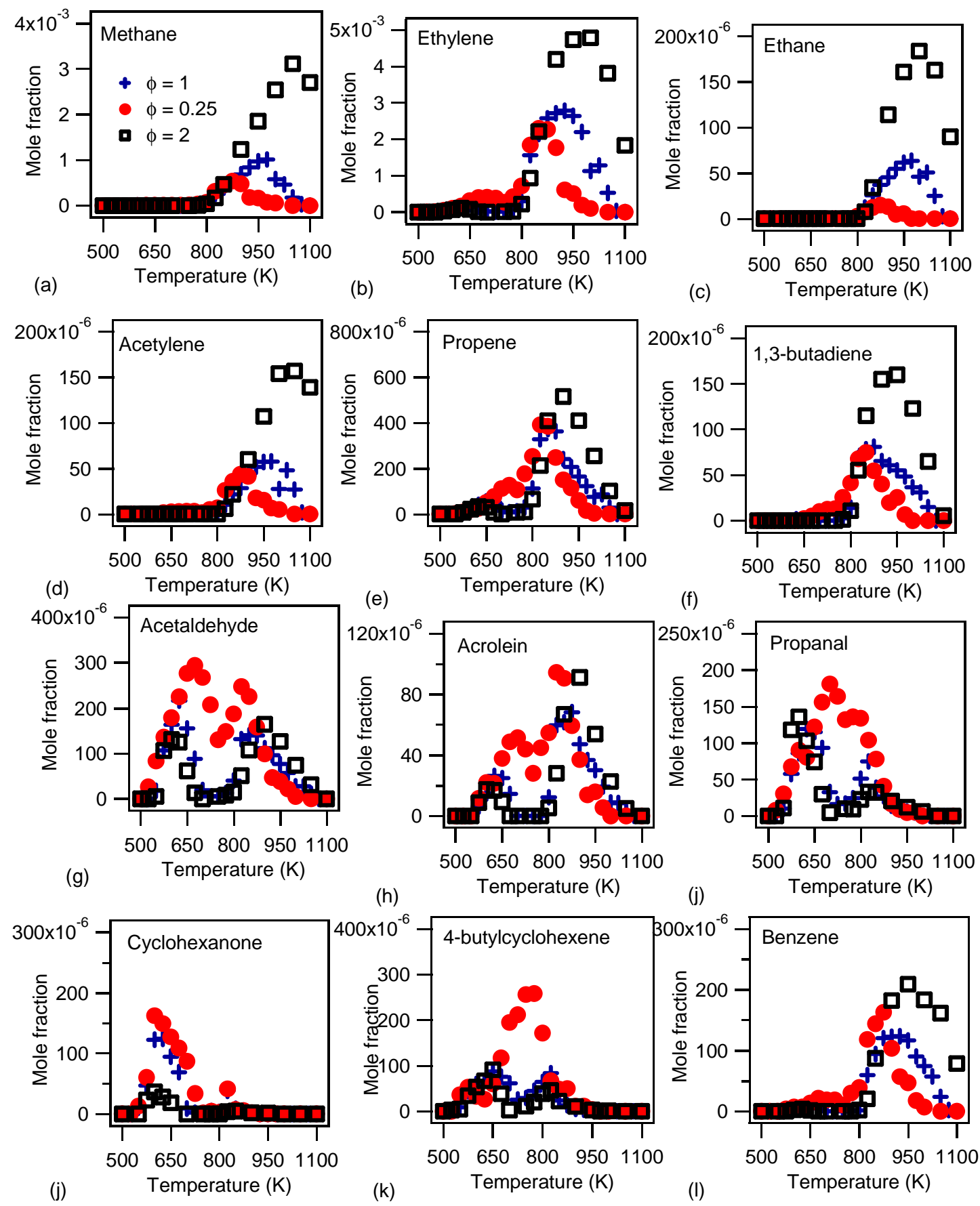

Figure 7: Oxidation of $n$-butylcyclohexane in a jet-stirred reactor at 1.067 bar. Influence of equivalence ratio on the evolution of the mole fractions of important products except carbon oxides

$$
\left(x_{\sigma C_{4} H_{9}}=0.004, \tau=2 \mathrm{~s}\right) \text {. }
$$

Selectivities (\%) are displayed in Table S1 in supplemental data. The carbon selectivity of a product is obtained by dividing the carbon content of the molecule by the total carbon content in reaction products (Equation (1)). The total carbon content in reaction products was calculated from the converted fuel mole fraction $\left(x_{\text {fuel }}^{\text {inlet }}-x_{\text {fuel }}^{\text {outlet }}\right)$ since all reaction products could not been quantified. 
$S_{i}=\frac{x_{i} \times n_{i}^{C}}{\sum_{j=1}^{n}\left(x_{j} \times n_{j}^{C}\right)} \times 100=\frac{x_{i} \times n_{i}^{C}}{\left(x_{\text {fuel }}^{\text {inlet }}-x_{\text {fuel }}^{\text {outet }}\right) \times n_{\text {fuel }}^{C}} \times 100$

equation(1)

with $x_{i}$ the mole fraction of reaction product $i, n_{i}^{C}$ the number of carbon atoms in reaction product $i$, $n_{f u e l}^{C}$ the number of carbon atoms in the fuel molecule, and $n$ the total number of reaction product.

The analysis of the data given in Table $\mathrm{S} 1$ shows that the selectivities of $\mathrm{CO}$ and $\mathrm{CO}_{2}$ significantly decrease with increasing the equivalence ratio whereas the opposite trend is observed for typical lowtemperature species with the same skeleton as the reactant (called $\mathrm{C}_{8} \mathrm{H}_{14}$ and $\mathrm{C}_{8} \mathrm{H}_{14} \mathrm{O}$ isomers in Table S1), and styrene. For other species (unsaturated hydrocarbons, aldehydes and ketones), the selectivity does not vary much and exhibits a maximum at $\varphi=1$. These observations show that mixtures with a high oxygen content display a higher reactivity, with a high formation of carbon oxides, and a lower formation of heavy low-temperature oxidation products (with the same skeleton as the reactant). As is shown in Figure 3, the formation of carbon monoxide derives from two additions with oxygen, it is why it is so significantly favored in lean mixtures. The rapid atmospheric degradation (Moriarty et al., 2003) of heavy low-temperature oxidation species could lead to the formation of toxic oxygenated products, such aldehydes. The reduced formation of these heavy species under lean conditions is a good point to promote the developments of cleaner advanced internal combustion engine strategies based on the use of low fuel/air ratio (Dec, 2009).

Table S2 displays selectivities at $950 \mathrm{~K}$ of hydrocarbons, $\mathrm{CO}, \mathrm{CO}_{2}$ and some oxygenated species. Acetaldehyde and $\mathrm{C}_{8} \mathrm{H}_{14} \mathrm{O}$ isomers are the main oxygenated reaction products (except $\mathrm{CO}$ and $\mathrm{CO}_{2}$ ) at high temperature. As already discussed, the conversion is almost total under lean conditions, whereas it is lower in stoichiometric (96\%) and rich (91\%) conditions. At high temperature, the equivalence ratio has also a strong effect on the product distribution as shown by the data presented in Table S2. In a general way, under the studied conditions, the selectivities of unburned species strongly increase with the equivalence ratio. As an example, the selectivity of ethylene increases from 2.9 at $\varphi=0.25$ to 23.5 at $\varphi=2$. The opposite trend is observed for $\mathrm{CO}_{2}$, the selectivity of which strongly decreases with the equivalence ratio. $\mathrm{CO}$, which is an intermediate between unburned species and $\mathrm{CO}_{2}$, exhibits a maximum selectivity under stoichiometric conditions. The fact that high equivalence ratios favor soot formation in diesel engines has long been known (Dec, 2009). This is confirmed by the results shown in Table S2 which show that the benzene selectivity increases from 0.936 at $\varphi=0.25$ to 2.15 at $\varphi=2$. Another type of pollutant having an impact on the troposphere chemistry (Nguyen et al., 2013) and which is rarely reported in oxidation kinetic studies (Herbinet and Battin-Leclerc, 2014), was observed 
in the present work for alkylcyclohexanes: acetic acid. Large mole fractions were measured at lowtemperature, as is shown in Figure 8 for $n$-butylcyclohexane. Its formation was notably favored in lean mixtures (see Table S1).

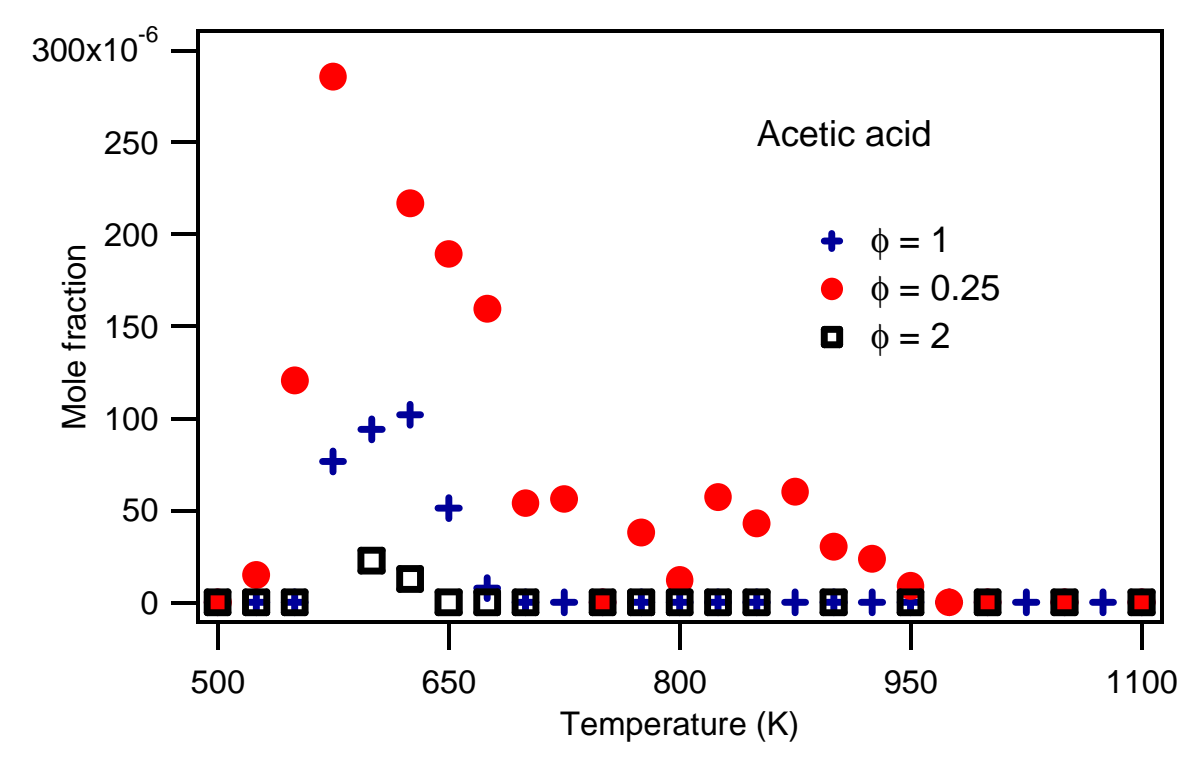

Figure 8: Oxidation of $n$-butylcyclohexane in a jet-stirred reactor at 1.067 bar. Influence of equivalence ratio on the evolution of the mole fractions of acetic acid $\left(x_{\varphi C_{4} H_{9}}=0.004, \tau=2 \mathrm{~s}\right)$.

\section{Influence of the pressure on reactivity and product formation}

The effect of varying the pressure from 1.067 to 10 bar has been studied for the oxidation of ethylbenzene, ethylcyclohexane and $n$-butylcyclohexane. Excel files giving the experimental mole fractions of all products analyzed during the oxidation of these three cyclic reactants are given as supplementary material.

Figure 9 presents a comparison between the results obtained at 1.067 and at 6 bar for the temperature evolution profiles of the mole fraction of fuel and some key products measured during the oxidation of ethylbenzene for the same fuel inlet mole fraction (0.005) in both cases. Simulations displayed in Figure 9 were computed using a model from the literature (Battin-Leclerc et al., 2015) showing an overall satisfactory agreement, apart from the formation of $C_{3}-C_{5}$ unsaturated compounds.

As shown in Figure 9a, the increase of the pressure led to a significant enhancement of the reactivity between 770 and $950 \mathrm{~K}$. At 6 bar, the reaction started at a temperature about $50 \mathrm{~K}$ lower and the fuel was fully consumed at a temperature about $100 \mathrm{~K}$ lower than at 1.067 bar. The effect on reactivity is also shown by the evolution of the evolution of the mole fraction of carbon dioxide (Figure 9c). 

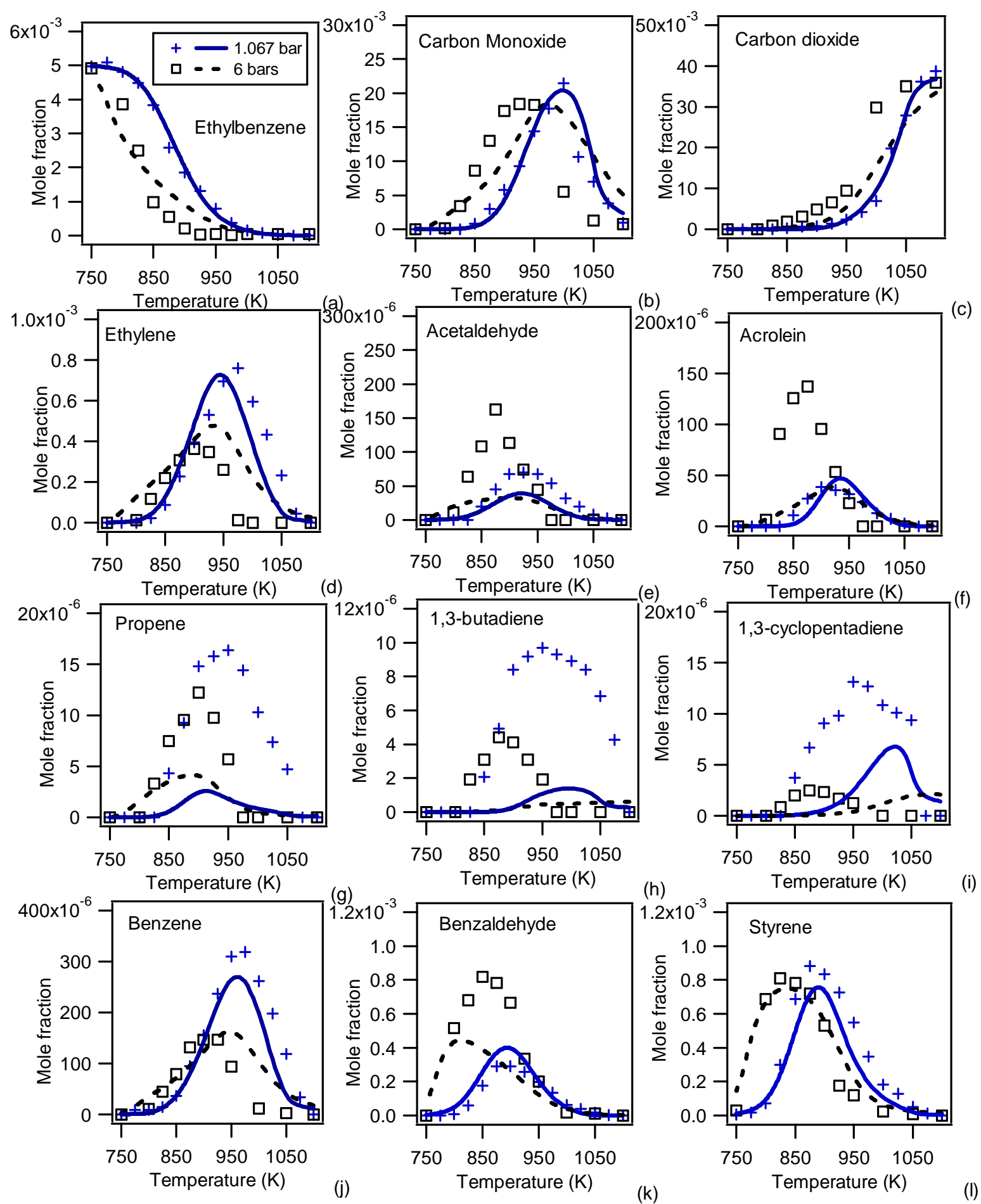

Figure 9: Oxidation of ethylbenzene in a jet-stirred reactor. Influence of pressure on the evolution of the conversion and the mole fractions of some important products $\left(x_{\varphi C_{2} H_{5}}=0.005, \tau=2 \mathrm{~s}, \varphi=1\right)$.

The rate constants of most involved reactions are not really influenced by the pressure change in the pressure domain of this study. However the increase of pressure favors bimolecular elementary steps (e.g. reactions with $\mathrm{O}_{2}$ molecules or with $\mathrm{HO}_{2} \bullet$ radicals which are particularly stable) through the increase of the related reaction rates which depends on species concentrations. According to the 
kinetic analysis of the model performed at $850 \mathrm{~K}$, the most sensitive reactions for the reactivity at both pressures are fuel $\mathrm{H}$-atom abstractions by $\mathrm{OH} \bullet$ radicals and reactions yielding $\mathrm{H}_{2} \mathrm{O}_{2}$. The main difference is the addition of phenyl radicals to $\mathrm{O}_{2}$ which is not sensitive at 1.067 bar and which is one of the most sensitive reactions at 6 bar. According to the rate of production analysis performed at 6 bar, phenyl radicals mainly comes from the decomposition of $\varphi(\mathrm{CO}) \bullet$ radicals $(72 \%)$ and of $\varphi-\mathrm{CH}_{2}-\mathrm{CH}_{2} \bullet$ fuel radicals. $\varphi(\mathrm{CO}) \bullet$ mainly comes from benzaldehyde $\mathrm{H}$-atom abstractions. Benzaldehyde comes from the decomposition of $\varphi-\mathrm{CH}(\mathrm{O} \bullet)-\mathrm{CH}_{3}$ radicals obtained from the decomposition of the $\varphi-\mathrm{CH}(\mathrm{OOH})-\mathrm{CH}_{3}$ hydroperoxide. This hydroperoxide is formed through the combination of fuel benzylic and $\mathrm{HO}_{2} \bullet$ radicals. Note that the pressure increase has almost no influence on the ratio of the different types of reactions consuming the fuel (ipso-additions, fuel benzylic $\mathrm{H}$-atom abstractions and fuel alkylic $\mathrm{H}$-atom abstractions). On the other hand, significant differences are observed for fuel radical consumption. As an example, for the benzylic fuel radical, the pressure increase favors its combination with $\mathrm{HO}_{2} \bullet$. radicals compared to its reaction with $\mathrm{O}_{2}$ to give styrene and $\mathrm{HO}_{2} \bullet$ (the contribution of the combination increases from 50 to $59 \%$ when pressure increases). For the other fuel radicals, the pressure effect is still more important. The pressure increase favors significantly the reaction with $\mathrm{O}_{2}$ yielding styrene and $\mathrm{HO}_{2} \bullet$ radicals (with a jump from 45 to $94 \%$ with increasing pressure) compared to the decompositions giving styrene $+\mathrm{H} \bullet$ and ethylene + phenyl•. Uncertainties in the kinetic parameters of the reactions of fuel radicals (particularly the combination of the benzylic with $\mathrm{HO}_{2} \bullet$ radicals) are likely responsible for the deviations observed between experimental and computed reactivity profiles.

While the same products were quantified at 1 and 6 bar, the increase of pressure has also some influence of the temperature evolution profiles of the mole fraction of intermediate products. For small hydrocarbons, such ethylene (Figure 9d), the maximum mole fraction was reached at a temperature around $100 \mathrm{~K}$ lower at 6 bar than at $1.067 \mathrm{bar}$, and the maximum value was significantly lower at high pressure. According to the rate of production analysis performed at $950 \mathrm{~K}$ (a temperature close to that of maximum mole fractions), ethylene formation pathways are similar at both pressures. The lower mole fractions spotted at 6 bar are explained by a higher consumption of this species as its formation flux is ten times larger at this pressure than that at 1.067 bar. This larger consumption is due to a larger gas-phase radical concentration at 6 bar. The same trend is observed for propene (Figure 9g), styrene (Figure 9l) and soot precursors, such as 1,3-butadiene (Figure 9h), 1,3-cyclopentadiene (Figure 9i), and benzene (Figure 9k).

The maximum mole fractions of oxygenated intermediates is larger at 6 bar than at 1.067 bar it can be seen for carbon monoxide (Figure 9b), and aldehydes, such acetaldehyde (Figure 9e), acrolein (Figure 
9f), and benzaldehyde (Figure 9k), with the maximum of formation obtained at a temperature about $80 \mathrm{~K}$ lower than at 1.067 bar. Note that the model well predicts the displacement of the maximum mole fraction towards lower temperatures when increasing pressure for benzaldehyde (Figure 9k), but under-estimates its mole fractions at 6 bar by a factor of about 2. One explanation for this could be uncertainties in kinetic parameters involved in the sequence of reactions starting from the consumption of the fuel benzylic radical.

Table S3 displays the carbon product selectivities obtained for ethylbenzene at 1 and 6 bar for experiments leading to the same fuel conversion (around 50\%). These data clearly show that there is a shift in the product distribution and that the increase of pressure globally favors the formation of oxygenated species: the sum of the selectivities of hydrocarbon products is lowered by $25 \%$ whereas that of oxygenated compounds (without $\mathrm{CO}$ and $\mathrm{CO}_{2}$ ) is increased by $84 \%$. Selectivities of $\mathrm{CO}$ and $\mathrm{CO}_{2}$ are almost not affected by the change in pressure.

As far as individual selectivities are concerned, noticeable increases are observed for acrolein, benzofuran, and benzaldehyde. $\mathrm{CO}_{2}$ and acetaldehyde selectivities are not affected, whereas $\mathrm{CO}$ is the only oxygenated product the selectivity of which is lower at 6 bar than at 1.067 bar. As far as hydrocarbons are concerned, selectivities of most species decrease with the pressure except for some species like cumene, 2-propenyl-benzene and $\alpha$-methyl-styrene. These $C_{9}$ aromatic species are derived from bimolecular combination reactions involving methyl radical and a radical obtained from styrene (the product with the largest selectivity at 6 bar).

Figure S2 in supplemental data presents another aspect of the influence of pressure: the position of intermediate zone in which the reactivity remains very weak is shifted towards lower temperature when the pressure increases. This is shown in Figure $\mathbf{S} 2$ for the two studied alkylcyclohexanes by the significant increase of the reactivity at $800 \mathrm{~K}$ when increasing the pressure from 1 to $10 \mathrm{bar}$, while hardly no change is spotted at $850 \mathrm{~K}$. This is due to the influence of pressure on the equilibrium of addition reactions to molecular oxygen: the higher the pressure, the lower the temperature where the formation of ROO• peroxy radicals is disfavored. 


\section{Conclusion}

This paper presents new experimental results obtained in a jet-stirred reactor at pressure from 1 to 10 bar for a series of $C_{8}-C_{12} n$-alkylbenzenes and a series of $C_{8}-C_{10} n$-alkylcyclohexanes for equivalence ratios from 0.25 to 2 . To facilitate the comparison between the reactivity of the five investigated compounds (i.e. ethylbenzene, ethylcyclohexane, $n$-butylbenzene, $n$-butylcyclohexane, and $n$ hexylbenzene), the experiments at a given pressure were performed with a constant inlet mole fraction of atoms of carbon. When available, literature models have been used to run simulations. Overall the agreement between experimental and computed alkylbenzene data was satisfactory. These models were used to performed kinetic analysis and to understand the effect of the size of the alkyl chain on the reactivity of alkylbenzenes.

The main conclusions can be summarized as below:

- Like the corresponding cetane numbers, the low-temperature reactivity (below $800 \mathrm{~K}$ ) of $n$-alkylbenzenes increases significantly when the size of the alkyl chain increases from 2 to 6 atoms of carbon, whereas the high-temperature reactivity remains mostly constant,

- like the corresponding cetane numbers, the low-temperature reactivity, as well as the high-temperature reactivity, of $n$-alkylcyclohexanes remains mostly constant when the size of the alkyl chain increases from 2 to 4 atoms of carbon,

- for a given size of the alkyl chain, $n$-alkylcyclohexanes are notably more reactive than $n$-alkylbenzenes, with a larger production of oxygenated species, such as toxic aldehydes for the naphthenic fuels, and a favored formation of soot precursors for the aromatic ones,

- at low-temperature, the equivalence ratio has a strong influence on the reactivity (the leaner the mixture, the higher the reactivity). A selectivity analysis showed that lean conditions disfavor the formation of olefins and oxygenated species with the same skeleton as the reactant, but favor that of $\mathrm{CO}$ and $\mathrm{CO}_{2}$,

- at high-temperature, the equivalence ratio has less effect on the reactivity but provoke important change in the product selectivity. Under rich conditions, the formation of unburned species (benzene and unsaturated hydrocarbons which are soot precursors and small carbonyl compounds such as acetaldehyde) is favored compared to that of $\mathrm{CO}_{2}$, and 
- at a given temperature and a given inlet fuel mole fraction, the pressure increase significantly favors the reactivity of these hydrocarbons and leads to a larger production of oxygenated species, such as toxic aldehydes and to a lower formation of soot precursors.

The results presented in this paper will be valuable for further model developments, as well as for formulating new diesel fuels for advanced and cleaner internal combustion engine strategies. The comparison between ethylbenzene experimental data and those computed using a literature model at 6 bar showed that the specific chemistry of alkylbenzenes still needs to be improved, with a particular attention needed to reactions of benzylic radicals. In the same way, models for the oxidation of alkylcyclohexanes do exist but they do not include the specific chemistry which is required to obtain correct predictions in the low-temperature regime. The modeling of this chemistry will require an important amount of work as kinetic parameter data bases are relatively poor as far as lowtemperature reactions of cyclanes are concerned.

\section{Acknowledgment}

This work has been supported by Saudi-Aramco.

\section{Supplementary materials}

Supplementary figures and tables (pdf file)

Experimental data (Excel spreadsheets)

\section{References}

Battin-Leclerc, F., 2008. Detailed chemical kinetic models for the low-temperature combustion of hydrocarbons with application to gasoline and diesel fuel surrogates, Prog. Energ. Combust. Sci. 34, 440-498.

Battin-Leclerc, F., Glaude, P. A., Warth, V., Fournet, R., Scacchi, G., Come, G. M, 2000. Computer tools for modelling the chemical phenomena related to combustion, Chem. Eng. Sci. 55, 2883-2893.

Battin-Leclerc, F., Herbinet, O., Glaude, P.-A., Fournet, R., Zhou, Z., Deng, L., Guo, H., Xie, M., Qi, F., 2010. Experimental Confirmation of the Low-Temperature Oxidation Scheme of Alkanes, Angew. Chem. Int. Ed. 49, 3169-3172.

Battin-Leclerc, F., Warth, V., Bounaceur, R., Husson, B., Herbinet, O., Glaude, P.-A., 2015. The oxidation of large alkylbenzenes: An experimental and modeling study, Proc. Combust. Inst. 35, 349-356.

Biet, J., Hakka, M.H., Warth, V., Glaude, P.-A., Battin-Leclerc, F., 2008. Experimental and Modeling Study of the Low-Temperature Oxidation of Large Alkanes. Energy Fuels 22, 2258-2269.

Curran, H.J., Gaffuri, P., Pitz, W.J., Westbrook, C.K., 1998. A comprehensive modeling study of n-heptane oxidation. Combust. Flame 114, 149-177.

Dagaut, P., Ristori, A., El Bakali, A., Cathonnet, M., 2002. Experimental and kinetic modeling study of the oxidation of n-propylbenzene, Fuel 81, 173-184.

Darcy, D., Nakamura, H., Tobin, C.J., Mehl, M., Metcalfe, W.K., Pitz, W.J., Westbrook, C.K., Curran, H.J., 2014. A high-pressure rapid compression machine study of n-propylbenzene ignition, Combust. Flame 161, 65-74.

Dec, J.E., 2009. Advanced compression-ignition engines-understanding the in-cylinder processes, Proc. 
Combust. Inst. 32, 2727-2742.

Diévart, P., Dagaut, P., 2011. The oxidation of n-butylbenzene: Experimental study in a JSR at 10 atm and detailed chemical kinetic modeling, Proc. Combust. Inst. 33, 209-216.

Guibet, J. C., 1999. Fuels and Engines, Publications de l'Institut Français du Petrole, Editions Technip, Paris.

Gudiyella, S., Brezinsky, K., 2012. High pressure study of n-propylbenzene oxidation, Combust. Flame 159, 940958.

Herbinet, O., Dayma, G., 2013. Jet-Stirred Reactors. In: Battin-Leclerc, F., Simmie, J.M., Blurock, E. (Eds.), Cleaner Combustion, Green Energy and Technology; Springer London, pp. 183-210.

Herbinet, O., Battin-Leclerc, F., 2014. Progress in understanding low-temperature organic compound oxidation using a jet-stirred reactor, Int. J. Chem. Kin. 46, 619-639.

Herbinet, O., Husson, B., Ferrari, M., Glaude, P.-A., Battin-Leclerc, F., 2013. Low temperature oxidation of benzene and toluene in mixture with n-decane, Proc. Combust. Inst. 34, 297-305.

Husson, B., Bounaceur, R., Tanaka, K., Ferrari, M., Herbinet, O., Glaude, P.A., Fournet, R., Battin-Leclerc, F., Crochet, M., Vanhove, G., Minetti, R., Tobin, C.J., Yasunaga, K., Simmie, J.M., Curran, H.J., Niass, T., Mathieu, O., Ahmed, S.S., 2012a. Experimental and modeling study of the oxidation of n-butylbenzene, Combust. Flame 159, 1399-1416.

Husson, B., Herbinet, O., Glaude, P.A., Ahmed, S.S., Battin-Leclerc, F., 2012b. Detailed Product Analysis during Low- and Intermediate-Temperature Oxidation of Ethylcyclohexane, J. Phys. Chem. A 116, 5100-5111.

Husson, B., Ferrari, M., Herbinet, O., Ahmed, S.S., Glaude, P.-A., Battin-Leclerc, F., 2013. New experimental evidence and modeling study of the ethylbenzene oxidation, Proc. Combust. Inst. 34, 325-333.

Kamimoto, T., Kobayashi, H., 1991. Combustion processes in diesel engines, Prog. Energ. Combust. Sci. 17, 163189.

Matras, D., Villermaux, J., 1973. Un réacteur continu parfaitement agité par jets gazeux pour l'étude cinétique de reactions chimiques rapides, Chem. Eng. Sci. 28, 129-137.

Mehl, M., Herbinet, O., Dirrenberger, P., Bounaceur, R., Glaude, P.-A., Battin-Leclerc, F., Pitz, W.J., 2015. Experimental and modeling study of burning velocities for alkyl aromatic components relevant to diesel fuels, Proc. Combust. Inst. 35, 341-348.

Moriarty, J., Sidebottom, H., Wenger, J., Mellouki, A., Le Bras, G., 2003. Kinetic Studies on the Reactions of Hydroxyl Radicals with Cyclic Ethers and Aliphatic Diethers. J. Phys. Chem. A 107, 1499-1505.

Mueller, C.J., Cannella, W.J., Bruno, T.J., Bunting, B., Dettman, H.D., Franz, J.A., Huber, M.L., Natarajan, M., Pitz, W.J., Ratcliff, M.A., Wright, K., 2012. Methodology for formulating diesel surrogate fuels with accurate compositional, ignition-quality, and volatility characteristics, Energ. Fuels 26, 3284-3303.

Nakamura, H., Darcy, D., Mehl, M., Tobin, C.J., Metcalfe, W.K., Pitz, W.J., Westbrook, C.K., Curran, H.J., 2014. An experimental and modeling study of shock tube and rapid compression machine ignition of $n$-butylbenzene/air mixtures, Combust. Flame 161, 49-64.

Natelson, R.H., Kurman, M.S., Cernansky, N.P., Miller, D.L., 2011. Low temperature oxidation of nbutylcyclohexane, Combust. Flame 158, 2325-2337.

Nguyen, T.L., Xue, B.C., Ellison, G.B., Stanton, J.F., 2013. Theoretical Study of Reaction of Ketene with Water in the Gas Phase: Formation of Acetic Acid?, J. Phys. Chem. A 117, 10997-11005.

Pitz, W.J., Mueller, C.J., 2011. Recent progress in the development of diesel surrogate fuels. Prog. Energ. Combust. Sci. 37, 330-350.

Pousse, E., Glaude, P.A., Fournet, R., Battin-Leclerc, F., 2009. A lean methane premixed laminar flame doped with components of diesel fuel: I. n-Butylbenzene, Combust. Flame 156, 954-974.

Pousse, E., Porter, R., Warth, V., Glaude, P.A., Fournet, R., Battin-Leclerc, F., 2010. Lean methane premixed laminar flames doped by components of diesel fuel: II. $n$-Propylcyclohexane, Combust. Flame 157, 75-90.

Ranzi, E., Gaffuri, P., Faravelli, T., Dagaut, P., 1995. A wide-range modeling study of n-heptane oxidation. Combust. Flame 103, 91-106.

Ristori, A., Dagaut, P., Bakali, A.E., Cathonnet, M., 2001. The oxidation of n-propylcyclohexane: Experimental results and kinetic modeling, Combust. Sci. Technol. 165, 197-228.

Roubaud, A., Minetti, R., Sochet, L.R., 2000. Oxidation and combustion of low alkylbenzenes at high pressure: comparative reactivity and auto-ignition, Combust. Flame 121, 535-541. 
Santana, R.C., Do, P., Santikunaporn, M., Alvarez, W., Taylor, J., Sughrue, E., Resasco, D., 2006. Evaluation of different reaction strategies for the improvement of cetane number in diesel fuels, Fuel 85, 643-656.

Sarathy, S.M., Westbrook, C.K., Mehl, M., Pitz, W.J., Togbe, C., Dagaut, P., Wang, H., Oehlschlaeger, M.A., Niemann, U., Seshadri, K., Veloo, P.S., Ji, C., Egolfopoulos, F.N., Lu, T., 2011. Comprehensive chemical kinetic modeling of the oxidation of 2-methylalkanes from $C_{7}$ to $C_{20}$. Combust. Flame 158, 2338-2357.

Serinyel, Z., Herbinet, O., Frottier, O., Dirrenberger, P., Warth, V., Glaude, P.A., Battin-Leclerc, F., 2013. An experimental and modeling study of the low- and high-temperature oxidation of cyclohexane, Combust. Flame 160, 2319.

Tranchant, J., Gardais, J.F., Gorin, P., Serpinet, J., Untz, G., 1982. Manuel pratique de chromatographie en phase gazeuse, Editions Masson, 1982, Paris, France.

Xiao, G., Zhang, Y., Lang, J., 2013. Kinetic modeling study of the ignition process of homogeneous charge compression ignition engine fueled with three-tomponent diesel surrogate, J. Ind. Eng. Chem. Res. 52, 37323741.

Wang, H., Dames, E., Sirjean, B., Sheen, D. A., Tango, R., Violi, A., Lai, J. Y. W., Egolfopoulos, F. N., Davidson, D. F., Hanson, R. K., Bowman, C. T., Law, C. K., Tsang, W., Cernansky, N. P., Miller, D. L., Lindstedt, R. P., 2010. A high-temperature chemical kinetic model of n-alkane (up to n-dodecane), cyclohexane, and methyl-, ethyl-, npropyl and n-butyl-cyclohexane oxidation at high temperatures, JetSurF version 2.0 (http://web.stanford.edu/group/haiwanglab/JetSurF/JetSurF2.0/index.html).

Wang, H., 2011. Formation of nascent soot and other condensed-phase materials in flames, Proc. Combust. Inst. 33, 41-67.

Zádor, J., Taatjes, C.A., Fernandes, R.X., 2011. Kinetics of elementary reactions in low-temperature autoignition chemistry, Prog. Energ. Combust. Sci. 37, 371-421. 